\title{
Grizzly/FAVOR Interface Project Report
}

Prepared by

T.L. Dickson, P.T. Williams, S. Yin, H.B. Klasky, S. K. Tadinada, B.R. Bass

Oak Ridge National Laboratory

Prepared for

J.T. Busby and B.D. Wirth

Light Water Reactor Sustainability Program

Risk-Informed Safety Margin Characterization

Approved for public release;

distribution is unlimited. 


\title{
DOCUMENT AVAILABILITY
}

Reports produced after January 1, 1996, are generally available free via the U.S. Department of Energy (DOE) Information Bridge.

Web site http://www.osti.gov/bridge

Reports produced before January 1, 1996, may be purchased by members of the public from the following source.

\author{
National Technical Information Service \\ 5285 Port Royal Road \\ Springfield, VA 22161 \\ Telephone 703-605-6000 (1-800-553-6847) \\ TDD 703-487-4639 \\ Fax 703-605-6900 \\ E-mail info@ntis.gov \\ Web site http://www.ntis.gov/support/ordernowabout.htm
}

Reports are available to DOE employees, DOE contractors, Energy Technology Data Exchange (ETDE) representatives, and International Nuclear Information System (INIS) representatives from the following source.

Office of Scientific and Technical Information

P.O. Box 62

Oak Ridge, TN 37831

Telephone 865-576-8401

Fax 865-576-5728

E-mail reports@osti.gov

Web site http://www.osti.gov/contact.html

This report was prepared as an account of work sponsored by an agency of the United States Government. Neither the United States Government nor any agency thereof, nor any of their employees, makes any warranty, express or implied, or assumes any legal liability or responsibility for the accuracy, completeness, or usefulness of any information, apparatus, product, or process disclosed, or represents that its use would not infringe privately owned rights. Reference herein to any specific commercial product, process, or service by trade name, trademark, manufacturer, or otherwise, does not necessarily constitute or imply its endorsement, recommendation, or favoring by the United States Government or any agency thereof. The views and opinions of authors expressed herein do not necessarily state or reflect those of the United States Government or any agency thereof. 


\section{Grizzly/FAVOR Interface \\ Project Report}

Manuscript Completed: June 2013

Date Published: June 2013

Authors:

T.L. Dickson, P.T. Williams, S. Yin, H.B. Klasky, S. Tadinada, B.R. Bass

Prepared for

J. T. Busby and B. D. Wirth

Light Water Reactor Sustainability Program

Risk-Informed Safety Margin Characterization

Prepared by

OAK RIDGE NATIONAL LABORATORY

Oak Ridge, Tennessee 37831-6085

managed by

UT-BATTELLE, LLC

for the

U.S. DEPARTMENT OF ENERGY 
This page is intentionally left blank. 


\begin{abstract}
As part of the Light Water Reactor Sustainability (LWRS) Program, the objective of the Grizzly/FAVOR Interface project is to create the capability to apply Grizzly 3-D finite element (thermal and stress) analysis results as input to FAVOR probabilistic fracture mechanics (PFM) analyses. The one benefit of FAVOR to Grizzly is the PROBABILISTIC capability. This document describes the implementation of the Grizzly/FAVOR Interface, the preliminary verification and tests results and a user guide that provides detailed step-by-step instructions to run the program.
\end{abstract}




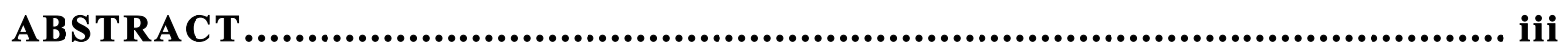

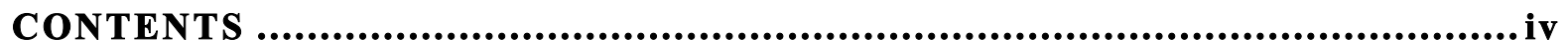

LIST OF FIGURES ................................................................ v

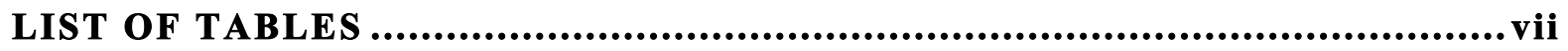

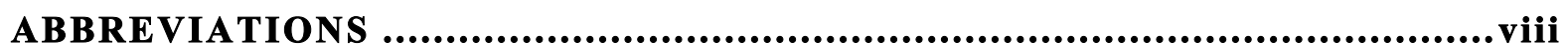

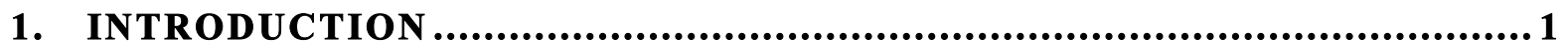

1.1 LWRS Overview ................................................................... 1

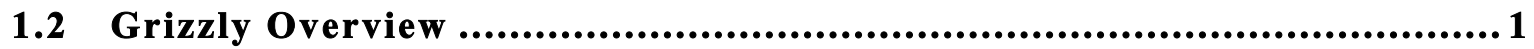

1.3 FAVOR Overview .................................................................. 2

1.4 GRIZZLY/FAVOR Interface Overview .................................... 2

2. Grizzly/FAVOR INTERFACE IMPLEMENTATION $\ldots \ldots \ldots \ldots \ldots \ldots \ldots \ldots \ldots \ldots . \ldots . \ldots . \ldots . \ldots . \ldots$

2.1 FAVOR - Computational Modules and Data Streams ..........................3

2.2 The Grizzly/FAVOR Interface ...............................................5

2.3 Grizzly/FAVOR Interface Input Description ..................................6

2.4 Grizzly/FAVOR Interface Output Files....................................... 17

2.5 Grizzly/FAVOR Interface Software Engineering Metrics ................... 20

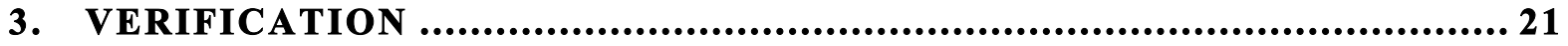

3.1 Initial Benchmarking of FAVOR and Grizzly................................. 21

3.2 Initial Testing of the Grizzly -FAVOR Interface ........................... 27

4. Grizzly/FAVOR INTERFACE USER GUIDE ................................... 35

4.1 Grizzly/FAVOR Interface Distribution .................................... 35

4.2 Hardware and SOFTWARE Requirements ................................... 35

4.3 Running the Grizzly/FAVOR Interface ...................................... 37

4.4 Contacts.......................................................................... 45

5. CONCLUSIONS AND FUTURE SUGGESTIONS ............................. 46

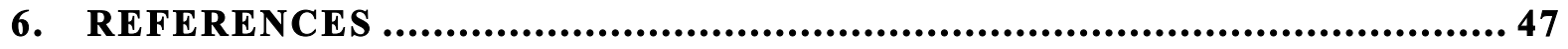




\section{LIST OF FIGURES}

\section{Figure}

\section{Page}

Figure 1. FAVOR data streams flow through three modules: (1) FAVLoad, (2) FAVPFM, and (3) FAVPost.

Figure 2. The FAVOR load generator module FAVLoad performs deterministic analyses for a range of thermal-hydraulic transients.

Figure 3. The FAVPFM module takes output from FAVLoad and user-supplied data on flaw distributions and embrittlement of the RPV beltline and generates PFMI and PFMF arrays...5 Figure 4. Implementation of the Grizzly/FAVOR interface.

Figure 5 Beaver Valley transient sequence 130 thermal hydraulic boundary condition - sever re-pressurization- is a dominant transient generated by RELAP5.

Figure 6 Probability distribution function for the transient frequency for Beaver Valley

transient sequence 130 .

Figure 7 Mutual verification of temperature time history solutions at point in wall thickness

for Beaver Valley transient sequence 130.

Figure 8 Mutual verification of axial stress time history solutions at point in wall thickness

for Beaver Valley transient sequence 130.

Figure 9 Mutual verification of hoop stress time history solutions at point in wall thickness

for Beaver Valley transient sequence 130.

Figure 10 Illustration of Beaver Valley transient sequence 007 - a severe cooldown transient

caused by surge line break.

Figure 11 Verification of Grizzly-FAVOR interface for temperature - time history at various

locations thru-the-wall thickness

Figure 12 Verification of Grizzly-FAVOR interface for axial stress - time history at various

locations thru-the-wall thickness

Figure 13 Verification of Grizzly-FAVOR interface for hoop stress-time history at various

locations thru-the-wall thickness.

Figure 14 Verification of Grizzly-FAVOR interface for spatial profiles of thru-wall

temperatures at different transient times.

Figure 15 Verification of Grizzly-FAVOR interface for spatial profiles of thru-wall axial stress at different transient times

Figure 16 Verification of Grizzly-FAVOR interface for spatial profiles of thru-wall hoop stress at different transient times.

Figure 17. Execution of the Grizzly/FAVOR interface module: (a) type in FAVOR_Grizzly_interface.exe at the line prompt and (b) respond to prompts for the input and output file names.

Figure 18. The Grizzly/FAVOR interface calculates thermal, stress, and applied $K_{I}$ loading for all of the transients defined in the input file.

Figure 19. Type FAVPFM.EXE at the Command Prompt to begin execution of the FAVPFM module.

Figure 20. FAVPFM prompts for the names of the (1) FAVPFM input file, (2) FAVLoadgenerated load-definition file, (3) FAVPFM output file, (4) flaw-characterization file for 
surface-breaking flaws in welds and plates, (5) flaw-characterization file for embedded flaws in welds, and (6) flaw-characterization file for embedded flaws in plates...........................42 Figure 21. FAVPFM continually writes out progress reports in terms of running average $\mathrm{CPI} / \mathrm{CPF}$ values for each transient as the code proceeds through the required number of RPV

trials.

Figure 22. Type in FAVPost at the Command Prompt to execute the FAVPost module.

FAVPost prompts for the (1) FAVPost input file, (2) CPI matrix file generated by FAVPFM, (3) CPF matrix file generated by FAVPFM, and (4) the FAVPost output file. Set the total number of simulations to be processed and build convergence tables, if required.... 


\section{LIST OF TABLES}

Table

Page

Table 1 Record Keywords and Parameter Fields for FAVLoad Input File............................... 8 


\begin{tabular}{ll} 
& \multicolumn{1}{c}{ ABBREVIATIONS } \\
FAVOR & $\begin{array}{l}\text { Fracture Analysis of Vessels - Oak Ridge } \\
\text { A MOOSE-based tool for simulating component ageing and damage evolution events } \\
\text { frizzly }\end{array}$ \\
for LWRS specific applications. \\
INL & Idaho National Laboratory \\
JFNK & Jacobian-Free Newton Krylov \\
LEFM & Linear-Elastic Fracture Mechanics \\
LWRS & Light Water Reactor Sustainability Program \\
MOOSE & Multi-Physics Object-Oriented Simulation Environment \\
NNSA & National Nuclear Security Administration \\
ORNL & Oak Ridge National Laboratory \\
PETSc & Portable, Extensible Toolkit for Scientific Computation Project \\
PDF & Probability Distribution Function \\
PFM & Probabilistic Fracture Mechanics \\
PTS & Pressurized Thermal Shock \\
RELAP5 & Reactor Excursion and Leak Analysis Program 5. \\
RPV & Reactor Pressure Vessel \\
SAPHIRE7 & Systems Analysis Programs for Hands-on Integrated Reliability Evaluation Version \\
SIFIC & 7. \\
& Stress-Intensity Influence Coefficient Factor
\end{tabular}





\section{INTRODUCTION}

This chapter presents overviews of the LWRS Program, Grizzly, FAVOR, and the Grizzly/FAVOR interface. It also emphasizes the benefits to Grizzly from FAVOR: the main benefit of FAVOR to Grizzly is the PROBABILISTIC capability.

\subsection{LWRS Overview}

The Light Water Reactor Sustainability (LWRS) Program [3] is designed to support the long-term operation (LTO) of existing domestic nuclear power generation with targeted collaborative research programs into areas beyond current short-term optimization opportunities. The LWRS Program focuses on four main areas: Materials Aging and Degradation, Advanced Instrumentation, Information, and Control Systems Technologies, Advanced Light Water Reactor Nuclear Fuels, and finally, Risk-Informed Safety Margin Characterization.

The Materials Aging and Degradation Pathway goal is to develop the scientific basis for understanding and predicting long-term environmental degradation behavior of materials in nuclear power plants and to provide data and methods to assess performance of systems, structures, and components essential to safe and sustained nuclear power plant operations.

The purpose of the Risk-Informed Safety Margin Characterization Pathway is to develop and deploy approaches to support the management of uncertainty in safety margins quantification to improve decision making for nuclear power plants. Management of uncertainty implies the ability to (a) understand and (b) control risks related to safety. Consequently, the RISMC Pathway is dedicated to improving both aspects of safety management.

\subsection{Grizzly Overview}

Grizzly [4] is a MOOSE-based tool for simulating component ageing and damage evolution events for LWRS specific applications. The Multi-physics Object Oriented Simulation Environment (MOOSE) is the Idaho National Laboratory's (INL) development and runtime environment for the solution of multi-physics systems that involve multiple physical models or multiple simultaneous physical phenomena. The systems are generally represented (modeled) as a system of fully coupled nonlinear partial differential equation systems (an example of a multi-physics system is the thermal feedback effect upon neutronics cross-sections where the cross-sections are a function of the heat transfer). Inside MOOSE, the Jacobian-Free Newton Krylov (JFNK) method is implemented as a parallel nonlinear solver that naturally supports effective coupling between physics equation systems (or Kernels). The physics Kernels are designed to contribute to the nonlinear residual, which is then minimized inside of MOOSE. MOOSE provides a comprehensive set of finite element support capabilities (libMesh) and provides for mesh adaptation and parallel execution. The framework heavily leverages software libraries from the U.S. Department of Energy Office of Science (DOE SC) and the National Nuclear Security Administration (NNSA), such as the nonlinear solver capabilities in either the Portable, Extensible Toolkit for Scientific Computation (PETSc) project or the Trilinos project.

Specifically, Grizzly will provide a simulation capability for:

- Reactor Metals (embrittlement, fatigue, corrosion, etc.), such as Reactor Pressure Vessel (RPV) and core internals

- Weldment integrity

- Concrete integrity 
subjected to a neutron flux, corrosive environment, and high temperatures and pressures. As with other applications utilizing the ever-growing library of MOOSE physics Kernels, Grizzly will heavily leverage the thermo-mechanics physics found in the BISON fuels performance application as a starting point.

\subsection{FAVOR Overview}

The Fracture Analysis of Vessels - Oak Ridge (FAVOR) computer code [1, 2] was developed and it is being maintained at Oak Ridge National Laboratory (ORNL) for the NRC. FAVOR includes implementations of significant advancements and refinements in technologies that have impacted established fracture mechanics and risk-informed methodologies. Updated computational methodologies have been developed through interactions between experts in the relevant disciplines of thermal hydraulics, probabilistic risk assessment, materials embrittlement, fracture mechanics, and inspection (flaw characterization). These methodologies have been and continue to be applied in the assessment and updating of regulations designed to insure that the structural integrity of aging and increasingly radiation-embrittled nuclear reactor pressure vessels (RPVs) is maintained throughout the licensing period of the reactor.

Contributors to the development of these methodologies include the U.S. Nuclear Regulatory Commission (NRC) staff, their contractors, and representatives from the nuclear industry. The analysis of Pressurized Thermal Shock (PTS) transients in nuclear power plants was the primary motivation for the initial development of FAVOR; earlier versions of FAVOR were limited to performing fracture analyses of pressurized water reactors (PWRs) subjected to cool-down transients.

On January 2013, the 12.1 version of FAVOR was deployed. FAVOR V. 12.1 represents a significant generalization over previous versions, because the problem class for FAVOR has been extended to encompass a broader range of events that include normal operational transients (start-up, shut-down, and leak-test) as well as upset conditions such as PTS. This latest version of FAVOR provides the capability to perform deterministic and risk-informed probabilistic fracture analyses of boiling water reactors (BWRs) and PWRs subjected to heat-up and / or cool-down transients.

The FAVOR computer code continues to evolve and to be extensively applied by analysts from the nuclear industry and regulators at the NRC to insure that the structural integrity of aging and increasingly radiation-embrittled nuclear reactor pressure vessels (RPVs) is maintained through-out the licensing period of the reactor. The FAVOR, v12.1, code represents the latest NRC-selected applications tool for performing such analyses.

FAVOR has extensive capability for calculation of applied $K_{I}$ for a wide variety of postulated defects - as required for fracture analysis. FAVOR PFM methodology is accepted by United States

Nuclear Regulatory Commission and has been used in updates of RPV regulations regarding relicensing of reactors from 40 to 60 years.

\subsection{GRIZZLY/FAVOR Interface Overview}

The objective of the Grizzly/FAVOR interface project is to create the capability to apply Grizzly 3-D finite element (thermal and stress) analysis results as input to FAVOR probabilistic fracture mechanics (PFM) analyses. The latter objective has been implemented by mapping the Grizzly output to the format required by the current FAVPFM module in FAVOR; from here, the execution flow of FAVOR remains unmodified. The main benefit of FAVOR to Grizzly is the PROBABILISTIC capability to calculate failures for structures.

In the following section, the Grizzly/FAVOR interface is described in detail. 


\section{Grizzly/FAVOR INTERFACE IMPLEMENTATION}

This section presents the implementation of the Grizzly/FAVOR interface.

\subsection{FAVOR - Computational Modules and Data Streams}

As presented in Figure 1, FAVOR is composed of three computational modules: (1) a deterministic load generator (FAVLoad), (2) a Monte Carlo PFM module (FAVPFM), and (3) a post-processor (FAVPost). Figure 1 also indicates the nature of the data streams that flow through these modules. The formats of the required user-input data files are discussed in detail in the FAVOR, v12.1: User's Guide [2].

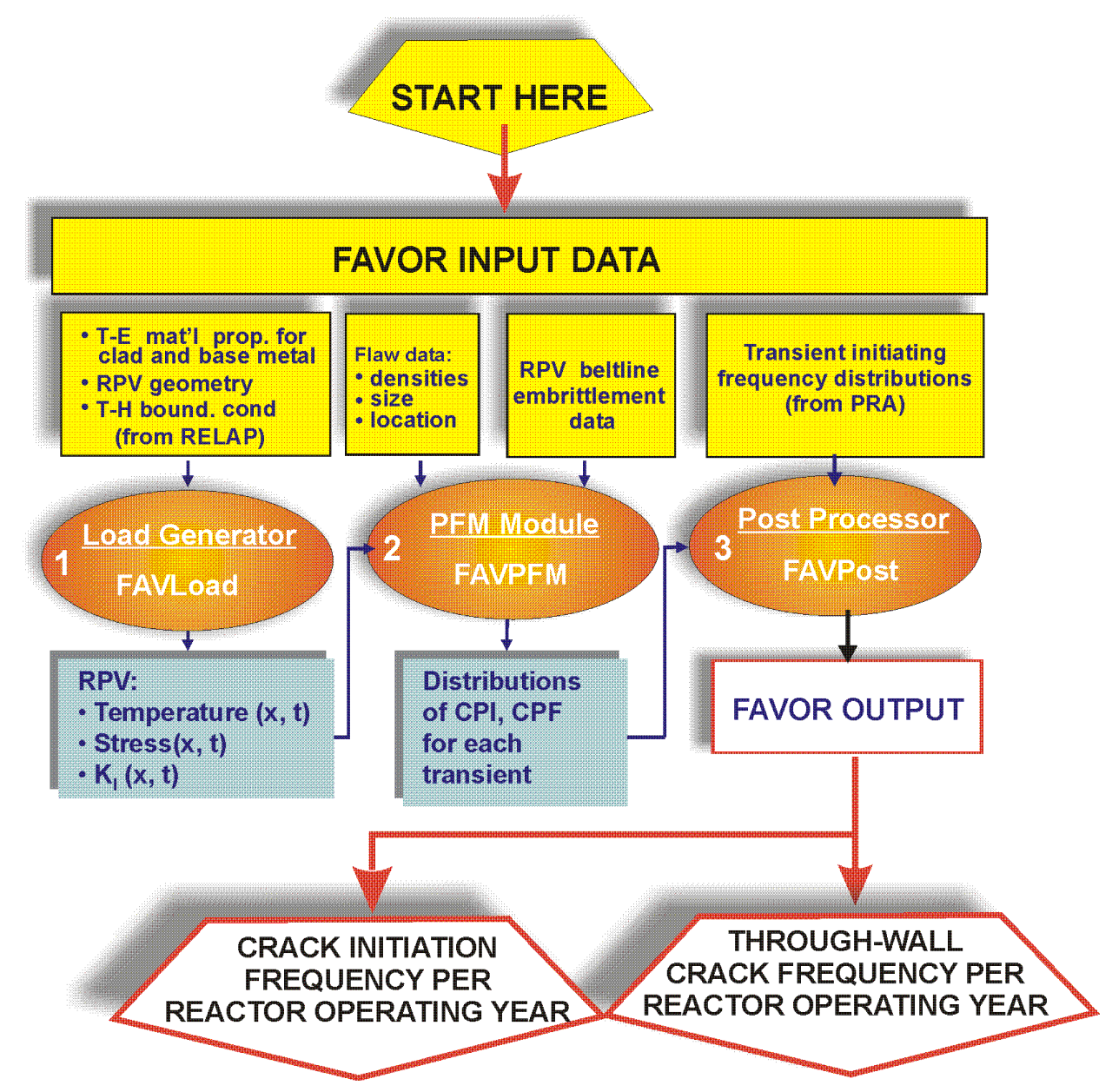

Figure 1. FAVOR data streams flow through three modules: (1) FAVLoad, (2) FAVPFM, and (3) FAVPost. 
The functional structure of the FAVOR load module, FAVLoad, is shown in Figure 2, where multiple thermal-hydraulic transients are defined in the input data. The number of transients that can be analyzed in a single execution of FAVLoad is dependent upon the memory capacity of the computer being used for the analysis. For each transient, deterministic calculations are performed to produce a load-definition input file for FAVPFM. These load-definition files include time-dependent through-wall temperature profiles, through-wall circumferential and axial stress profiles, and stressintensity factors (SIFs) for a range of axially- and circumferentially-oriented inner and external surface-breaking flaw geometries (both infinite- and finite-length).

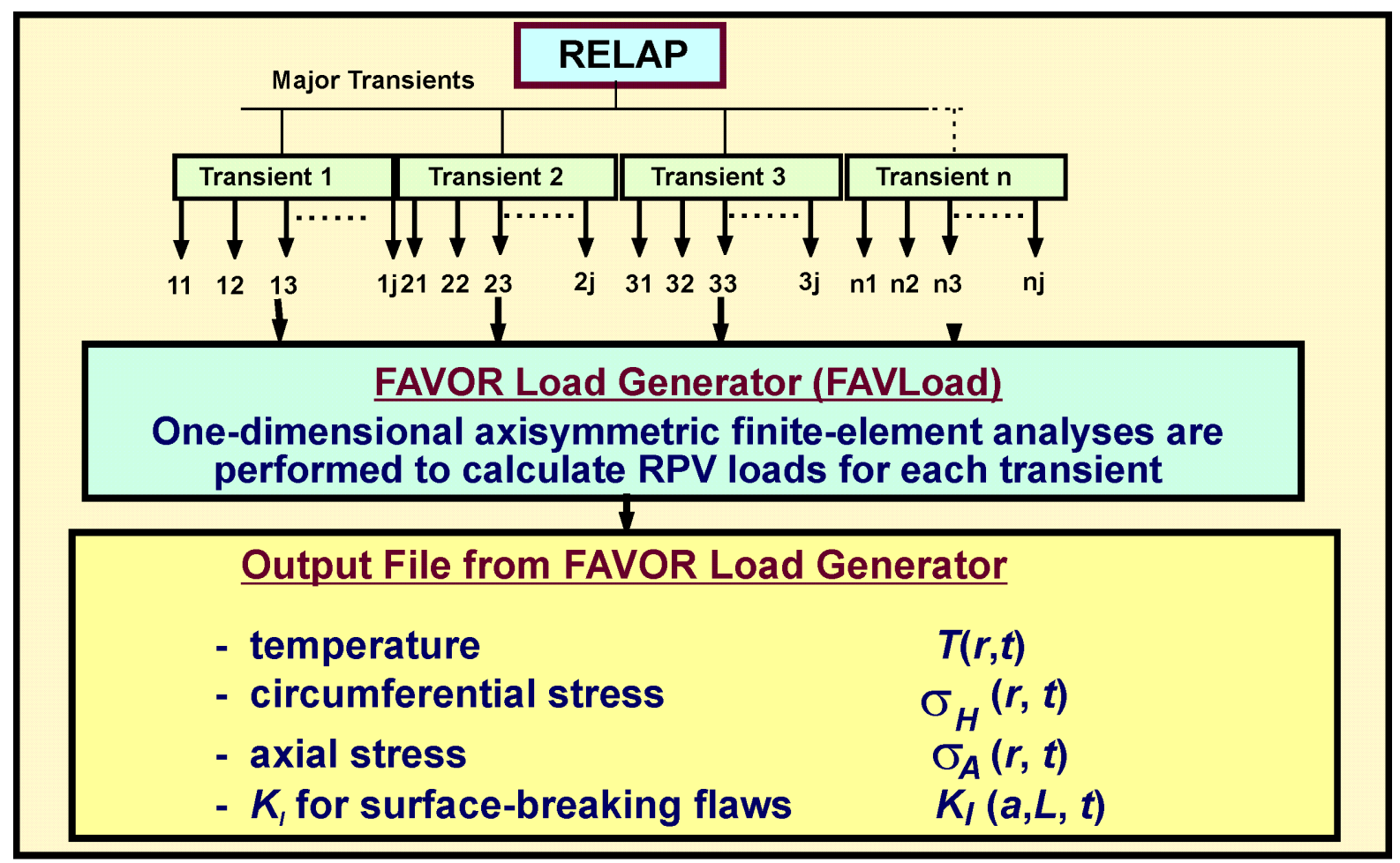

Figure 2. The FAVOR load generator module FAVLoad performs deterministic analyses for a range of thermal-hydraulic transients.

As shown in Figure 3, the FAVPFM module requires, as input, load-definition data from FAVLoad and user-supplied data on flaw distributions and embrittlement of the RPV beltline. FAVPFM then generates two matrices: (1) the conditional probability of crack initiation (PFMI) matrix and (2) conditional probability of through-wall cracking (PFMF) matrix. The $(i, j)$ th entry in each array contains the results of the PFM analysis for the $j$ th vessel simulation subjected to the $i$ th transient. 


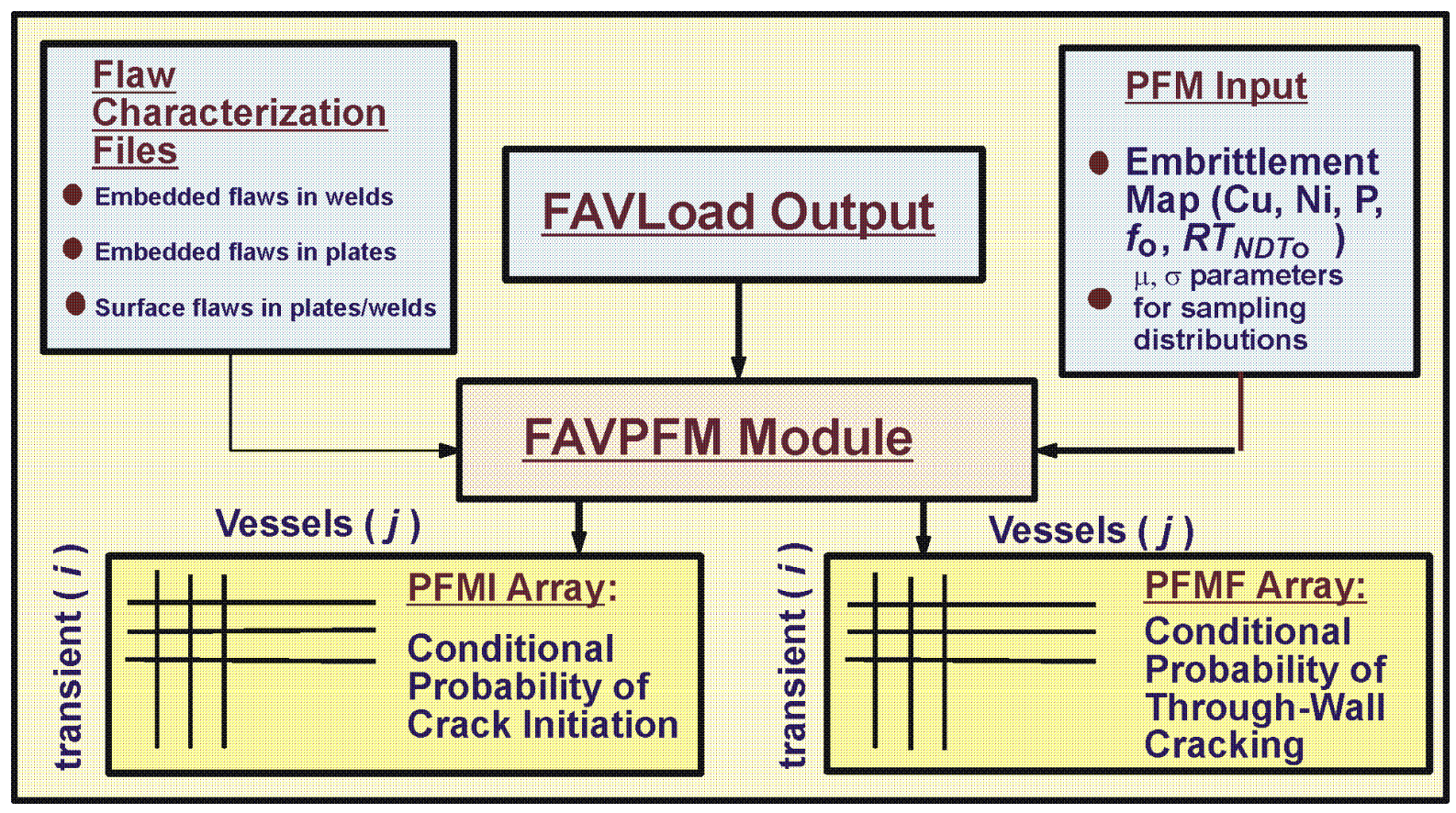

Figure 3. The FAVPFM module takes output from FAVLoad and user-supplied data on flaw distributions and embrittlement of the RPV beltline and generates PFMI and PFMF arrays.

\subsection{The Grizzly/FAVOR Interface}

The Grizzly/FAVOR interface has been implemented in the FAVLoad module described above.

The linear-elastic fracture mechanics (LEFM) methodologies applied in FAVOR require as input the stress-state and temperature fields for an unflawed structure. Using linear superposition, stressintensity influence coefficients (SIFICs) (stored in a library in FAVLoad) combined with the stressstate of an unflawed structure allow the determination of stress-intensity factors which contribute to the characterization of the driving forces on a postulated crack in a probabilistic assessment of the structural reliability of the RPV.

For the cracked structure under LEFM conditions, the singular stress field in the vicinity of the crack tip can be characterized by a single parameter. This one-parameter model has the form

$$
\begin{aligned}
\sigma_{\theta \theta} & =\frac{K_{I}}{\sqrt{2 \pi r}} \text { hoop stresses for axial flaws } \\
\sigma_{z z} & =\frac{K_{I}}{\sqrt{2 \pi r}} \text { axial stresses for circumferential flaws }
\end{aligned}
$$

where $r$ is the radial distance from the crack tip, and the crack plane is assumed to be a principal plane. The critical fracture parameter in Eq. (1) is the Mode I stress-intensity factor, $K_{I}$. When the conditions for LEFM are met, the problem of calculating the stress-intensity factor can be formulated solely in terms of the flaw geometry and the stress distribution of the uncracked structure.

In linking the Grizzly and FAVOR applications, it is intended to replace the 1-D stress and temperature fields calculated by the FAVLoad module with the fully 3-D solutions obtained by Grizzly. These 3-D stresses from Grizzly will serve as input to the Grizzly/FAVOR interface. The Grizzly/FAVOR interface performs the mapping and conversion of the Grizzly output to comply with 
FAVOR's FAVPFM module input format for its load definition file. From this step on, the flow and execution of FAVOR remains un-modified. The required modifications to FAVOR occur only in the FAVLoad module; therefore, the resulting Grizzly/FAVOR interface replaces the FAVLoad module as shown in Figure 4.

\section{Map GRIZZLY Results to the Format as Required by Current FAVPFM}

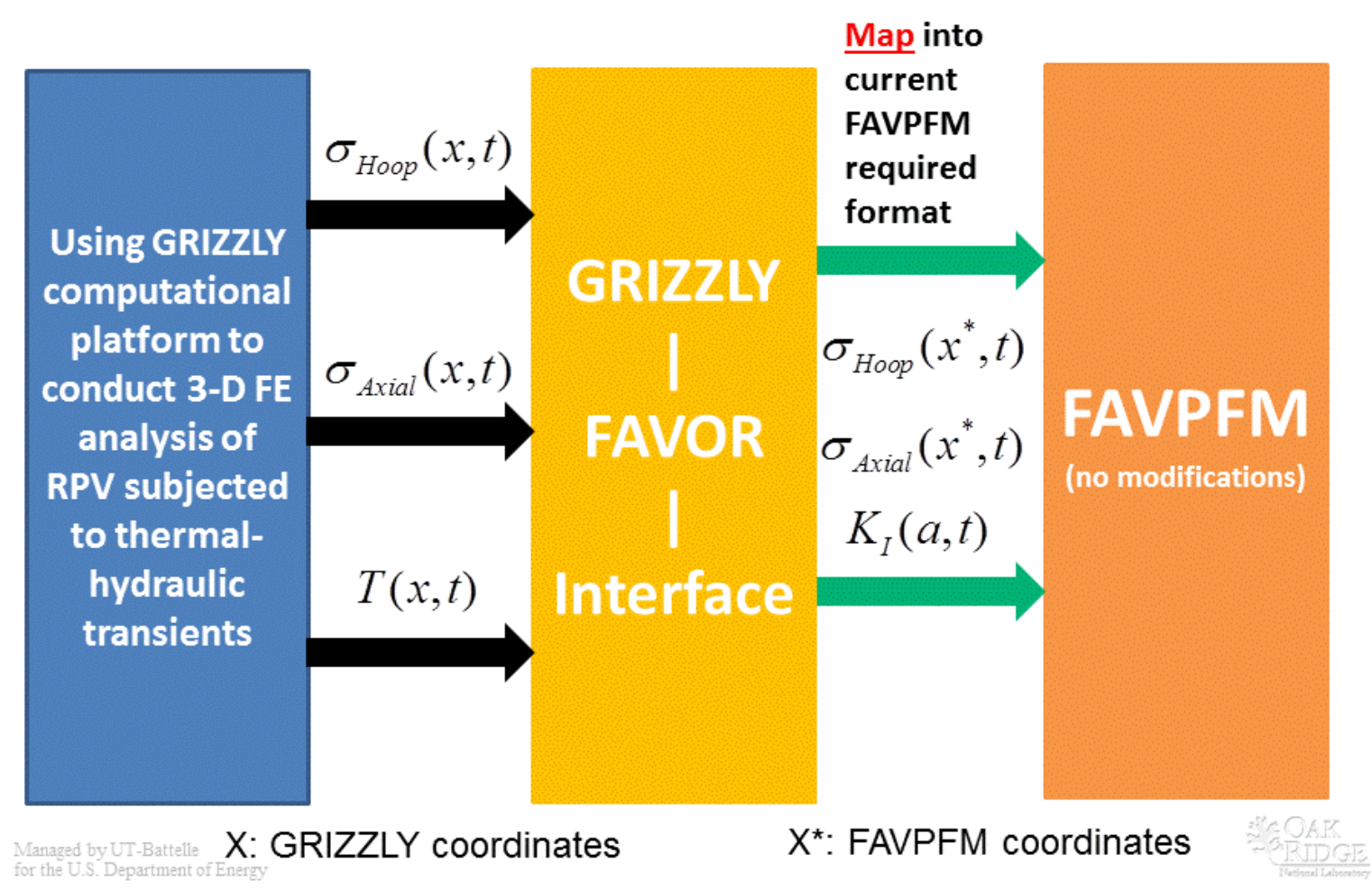

Figure 4. Implementation of the Grizzly/FAVOR interface.

\subsection{Grizzly/FAVOR Interface Input Description}

The FAVOR_Grizzly interface requires as input a single ASCII text file. In the following section, we present extracts of an input dataset for the FAVOR_Grizzly interface. As an example, the input file could be named FAVLoad1_GRI.in. As a proof of principle, this initial prototype will consider only one thermal-hydraulic transient. 
Note that the Grizzly mesh, temperature, axial stress, and hoop stresses are appended onto an existing FAVLoad input dataset. This format minimizes the number of modifications that have to be made to FAVLoad. The Grizzly/FAVLoad module reads in the Grizzly solutions (mesh, temps, and stresses) and maps them (by piecewise cubic spline fits) to locations that FAVLoad then uses in the calculation of $K_{I}$ values.

A total of 20 data records, listed in Table 1, are required in the Grizzly/FAVLoad input file, where each record may involve more than one line of data. A detailed description of each data record is given below. 
Table 1 Record Keywords and Parameter Fields for FAVLoad Input File

\begin{tabular}{|c|c|c|c|c|c|c|c|c|}
\hline 1 & GEOM & IRAD $=[$ in $]$ & $\mathbf{W}=[\mathbf{i n}]$ & CLTH=[in] & & \multirow[b]{2}{*}{ ALPHA $=\left[{ }^{\circ} \mathbf{F}^{-1}\right]$} & \multirow[b]{2}{*}{$\mathbf{N U}=[-]$} & \multirow[b]{2}{*}{$\mathrm{NTE}=[0 \mid 1]$} \\
\hline 2 & BASE & $\mathbf{K}=\left[\mathrm{Btu} / \mathbf{h r}-\mathbf{f t}-{ }^{\circ} \mathbf{F}\right]$ & $\mathbf{C}=\left[\right.$ Btu $/ \mathbf{l b m}-{ }^{\circ} \mathbf{F}$ & RHO $=\left[\mathbf{l b m} / \mathbf{f t}^{3}\right]$ & $E=[\mathbf{k s i}]$ & & & \\
\hline \multirow[t]{2}{*}{$2 \mathbf{a}$} & NBK & $\mathbf{N K}=[-]$ & if NTE $=1$ & & & & & \\
\hline & \multicolumn{6}{|c|}{ input NK data lines with $\{\mathrm{T}, \mathrm{K}(\mathrm{T})\}\left[{ }^{\circ} \mathrm{F}, \mathrm{Btu} / \mathrm{h}-\mathrm{ft}-{ }^{\circ} \mathrm{F}\right]$ pairs - one pair per line } & & \\
\hline \multirow[t]{2}{*}{ 2b } & NBC & $\mathrm{NC}=[-]$ & if NTE $=1$ & & & & & \\
\hline & \multicolumn{6}{|c|}{ input NC data lines with $\{\mathrm{T}, \mathrm{C}(\mathrm{T})\}\left[{ }^{\circ} \mathrm{F}, \mathrm{Btu} / \mathrm{lbm}-{ }^{\circ} \mathrm{F}\right]$ pairs - one pair per line } & & \\
\hline \multirow[t]{2}{*}{$2 \mathbf{c}$} & NBE & $\mathbf{N E}=[-]$ & if $\mathbf{N T E}=1$ & & & & & \\
\hline & \multicolumn{5}{|c|}{ input NE data lines with $\{\mathrm{T}, \mathrm{E}(\mathrm{T})\}\left[^{\circ} \mathrm{F}, \mathrm{ksi}\right]$ pairs - one pair per line } & & & \\
\hline \multirow[t]{2}{*}{ 2d } & NALF & $\mathbf{N A}=[-]$ & Tref0 $=\left[{ }^{\circ} \mathbf{F}\right]$ & if NTE=1 & & & & \\
\hline & \multicolumn{6}{|c|}{ input NA data lines with $\{\mathrm{T}, \operatorname{ALPHA}(\mathrm{T})\}\left[{ }^{\circ} \mathbf{F},{ }^{\circ} \mathbf{F}^{-1}\right]$ pairs - one pair per line } & & \\
\hline \multirow[t]{2}{*}{ 2e } & NNU & $\mathbf{N U}=[-]$ & if $\mathbf{N T E}=1$ & & & & & \\
\hline & \multicolumn{5}{|c|}{ input NU data lines with $\{\mathrm{T}, \mathrm{NU}(\mathrm{T})\}\left[{ }^{\circ} \mathrm{F},-\right]$ pairs - one pair per line } & & & \\
\hline 3 & CLAD & $\mathrm{K}=\left[\mathrm{Btu} / \mathrm{hr}-\mathrm{ft}-{ }^{\circ} \mathbf{F}\right]$ & $\mathbf{C}=\left[\mathbf{B t u} / \mathbf{l b m}-{ }^{\circ} \mathbf{F}\right]$ & RHO=[lbm/ft $\left.{ }^{3}\right]$ & $\mathbf{E}=[\mathbf{k s i}]$ & ALPHA $=\left[{ }^{\circ} \mathbf{F}^{-1}\right]$ & $\mathbf{N U}=[-]$ & $\mathbf{N T E}=[\mathbf{0} \mid \mathbf{1}]$ \\
\hline \multirow[t]{2}{*}{$3 \mathbf{a}$} & NCK & NK $=[-]$ & if $\mathbf{N T E}=1$ & & & & & \\
\hline & \multicolumn{6}{|c|}{ input NK data lines with $\{\mathrm{T}, \mathrm{K}(\mathrm{T})\}\left[{ }^{\circ} \mathrm{F}, \mathrm{Btu} / \mathrm{h}-\mathrm{ft}-{ }^{\circ} \mathrm{F}\right]$ pairs - one pair per line } & & \\
\hline \multirow[t]{2}{*}{$3 \mathbf{b}$} & NCC & $\mathrm{NC}=[-]$ & if $\mathbf{N T E}=1$ & & & & & \\
\hline & \multicolumn{6}{|c|}{ input $\mathrm{NC}$ data lines with $\{\mathrm{T}, \mathrm{C}(\mathrm{T})\}\left[^{\circ} \mathrm{F}, \mathrm{Btu} / \mathrm{lbm}-^{\circ} \mathrm{F}\right]$ pairs - one pair per line } & & \\
\hline $3 \mathbf{c}$ & NCE & $\mathbf{N E}=[-]$ & if NTE $=1$ & & & & & \\
\hline & input NE & data lines with $\{T$, & $\mathbf{E}(\mathbf{T})\}\left[{ }^{\mathrm{O}} \mathbf{F}, \mathbf{k s i}\right] \mathbf{p}$ & pairs - one pair pe & r line & & & \\
\hline 3d & NALF & $\mathbf{N A}=[-]$ & Tref0 $=\left[{ }^{\circ} \mathbf{F}\right]$ & if NTE=1 & & & & \\
\hline & input NA & data lines with $\{\mathbf{T}$, & $\operatorname{ALPHA}(\mathbf{T})\}\left[{ }^{\circ} \mathbf{F}\right.$ & ${ }^{\circ} \mathbf{F}^{-1}$ ] pairs - onc & pair per & ine & & \\
\hline $3 \mathbf{e}$ & NNU & $\mathbf{N U}=[-]$ & if NTE $=1$ & & & & & \\
\hline & input $\mathbf{N U}$ & data lines with $\{\mathbf{T}$, & $\mathbf{N U}(\mathbf{T})\}\left[{ }^{\circ} \mathbf{F},-\right] \mathbf{F}$ & pairs - one pair p & r line & & & \\
\hline 4 & SFRE & $\mathbf{T}=\left[{ }^{\circ} \mathbf{F}\right]$ & $\mathbf{C F P}=[\mathbf{0} \mid \mathbf{1}]$ & & & & & \\
\hline 5 & RESA & NRAX $=[-]$ & & & & & & \\
\hline 6 & RESC & NRCR=[-] & & & & & & \\
\hline 7 & TIME & TOTAL $=[\mathrm{min}]$ & DT $=[\mathbf{m i n}]$ & & & & & \\
\hline 8 & NPRA & NTRAN $=[-]$ & & & & & & \\
\hline & Repeat da & ta records 9 throug & gh 12 for each $N^{\prime}$ & TRAN transients & & & & \\
\hline 9 & TRAN & ITRAN $=[-]$ & ISEQ $=[-]$ & & & & & \\
\hline 10 & NHTH & $\mathrm{NC}=[-]$ & & & & & & \\
\hline & input $\mathrm{NC}$ & data lines with $\{t$, & $h(t)\}[\min$, Btu & $\left.\mathrm{i} / \mathbf{h r}-\mathrm{ft}^{2}-^{\circ} \mathrm{F}\right]$ pairs & one pair & per line & & \\
\hline 11 & NTTH & $\mathbf{N T}=[-]$ & & & & & & \\
\hline & input NT & lata lines with ( $t$, & $T(t))\left[\min ,{ }^{\circ} \mathbf{F}\right]$ & pairs - one pair $p$ & er line & & & \\
\hline & or & & & & & & & \\
\hline 11 & NTTH & NT $=101$ & & & & & & \\
\hline & STYL & TINIT $=\left[{ }^{\circ} \mathbf{F}\right]$ & TFINAL $=\left[{ }^{\circ} \mathbf{F}\right]$ & BETA $=\left[\min ^{-1}\right]$ & & & & \\
\hline 12 & NPTH & $\mathbf{N P}=[-]$ & & & & & & \\
\hline & input NP & data lines with ( $t$, & $P(t))[\mathrm{min}, \mathrm{ksi}]$ & pairs - one pair & er line & & & \\
\hline & Outpu & t from GRIZZLY 3 & 3D simulation of & RPV & & & & \\
\hline 13 & GN & TI NTIMES_GF & $\mathbf{R I}=[-]$ & & & & & \\
\hline 14 & GN & ME NUMNP_GR & $\mathbf{R I}=[-]$ & & & & & \\
\hline 15 & input & NTIMES_GRI data & lines with (time & _s tep, time) $[-$, mi & nutes ] & & & \\
\hline 16 & input & NUMNP_GRI data & lines with the ra & adial distance fro & $n$ the inn & r wall [inches] & & \\
\hline 17 & input & NTIMES_GRI data & lines with the in & nternal press ure & for each & RIZZLY time st & p [ksi] & \\
\hline 18 & input & NTIMES_GRI x NL & UMNP_GRI data & lines the thru-wa & Il temper & ture profiles for & ach time & tep [F] \\
\hline 19 & input & NTIMES_GRI x NI & UMNP_GRI data & lines the thru-wa & Il hoop st & ess profiles for & ach time s & tep [KSI] \\
\hline 20 & input & NTIMES_GRI x NI & UMNP_GRI data & lines the thru-wa & Il axial st & ess profiles for & ach time $s$ & tep [KSI] \\
\hline
\end{tabular}




\section{Record 1 - GEOM}

Record No. 1 inputs vessel geometry data, specifically the internal radius, IRAD, in inches, the wall thickness (inclusive of cladding), $\mathbf{W}$, in inches, and the cladding thickness, CLTH, in inches. The thickness of the base metal is, therefore, W- CLTH.

EXAMPLE

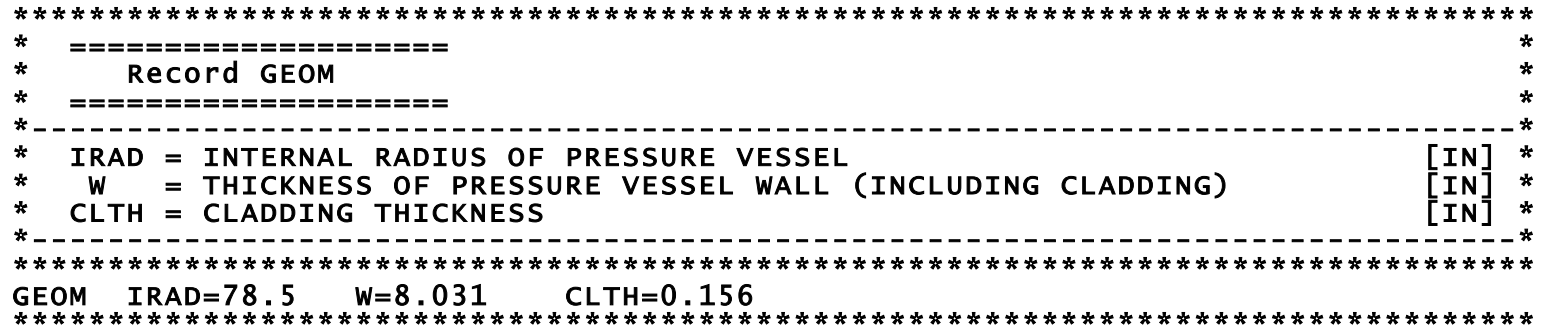

\section{Records 2 and 3- BASE and CLAD}

Records 2 and 3 input thermo-elastic property data for the base (typically a ferritic steel) and cladding (typically an austenitic stainless steel), respectively: thermal conductivity, $\mathbf{K}$, in $\mathrm{Btu} / \mathrm{hr}-\mathrm{ft}-{ }^{\circ} \mathrm{F}$, C, mass-specific heat capacity in Btu/lbm- ${ }^{\circ} \mathrm{F}$, mass density, RHO, in $1 \mathrm{bm} / \mathrm{ft}^{3}$, Young's modulus of elasticity, E, in ksi, coefficient of thermal expansion, ALPHA, in ${ }^{\circ} \mathrm{F}^{-1}$, and Poisson's ratio, NU. All property data are assumed to be independent of temperature if $\mathbf{N T E}=\mathbf{0}$.

\section{EXAMPLE}

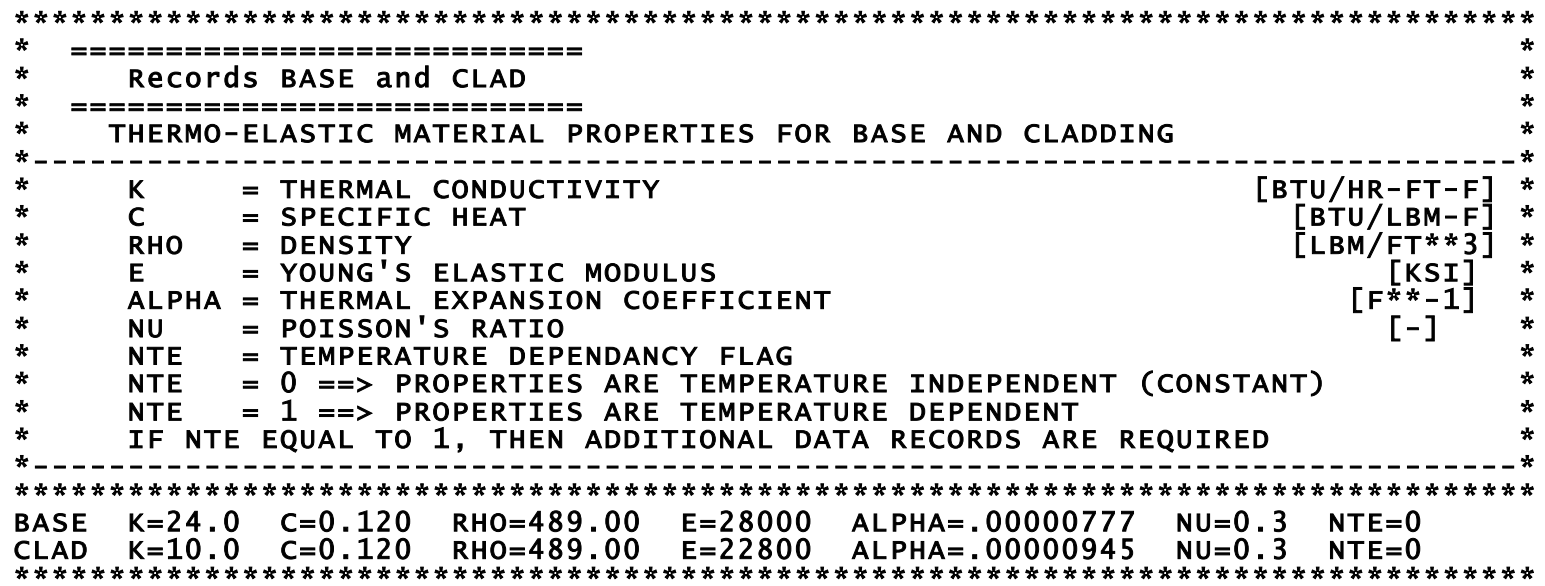

If $\mathbf{N T E}=1$ on Records 2 or 3, then tables of temperature-dependent properties will be input.

\section{EXAMPLE}

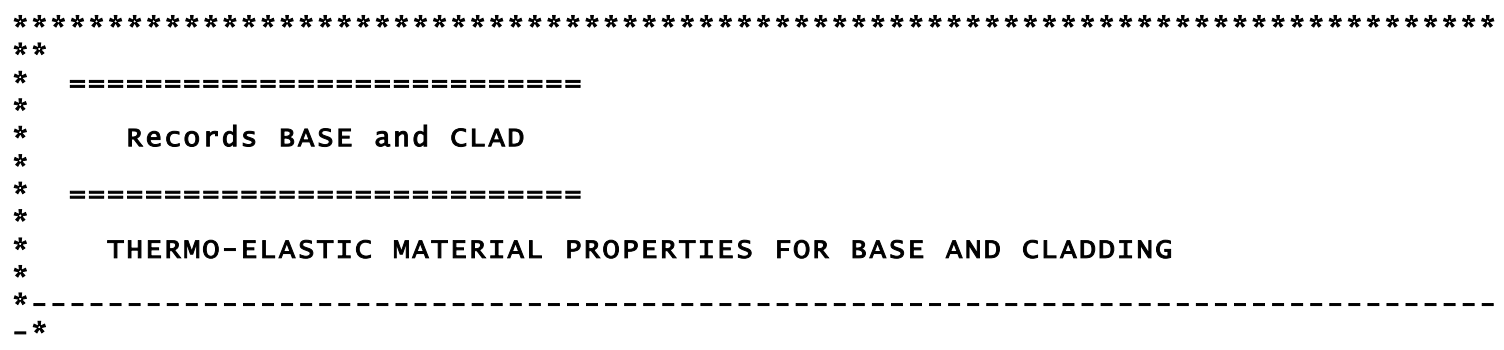




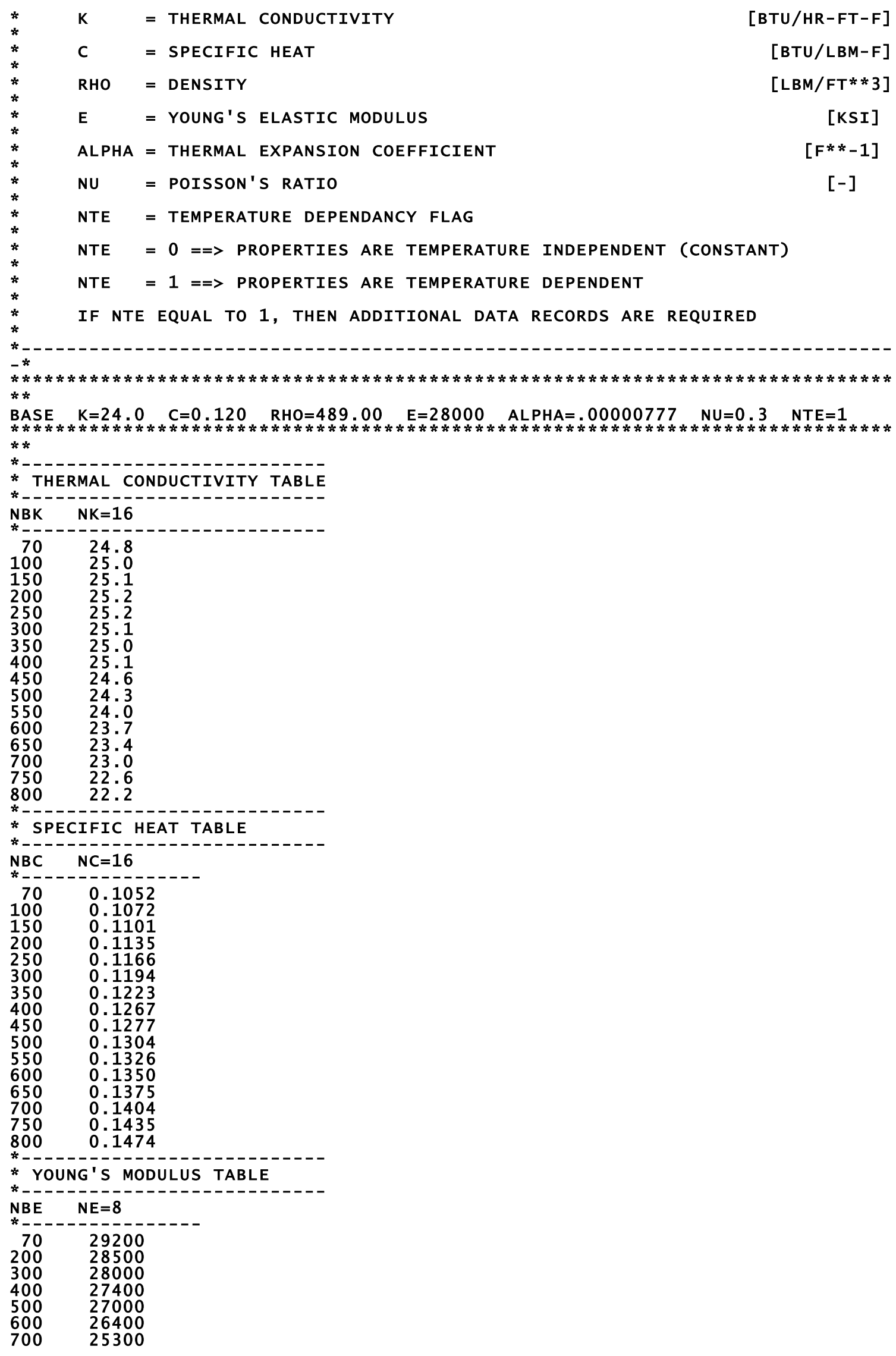




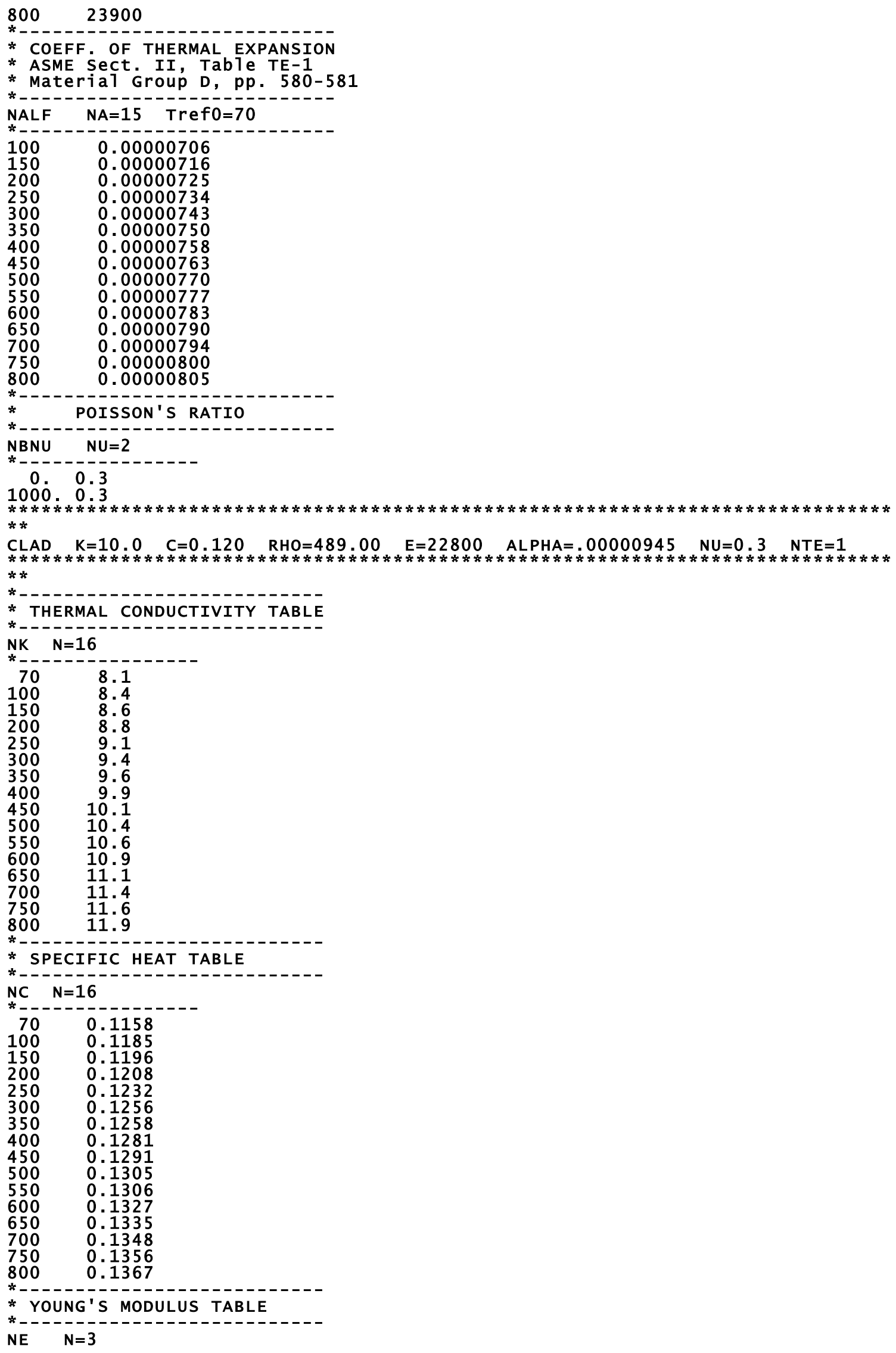




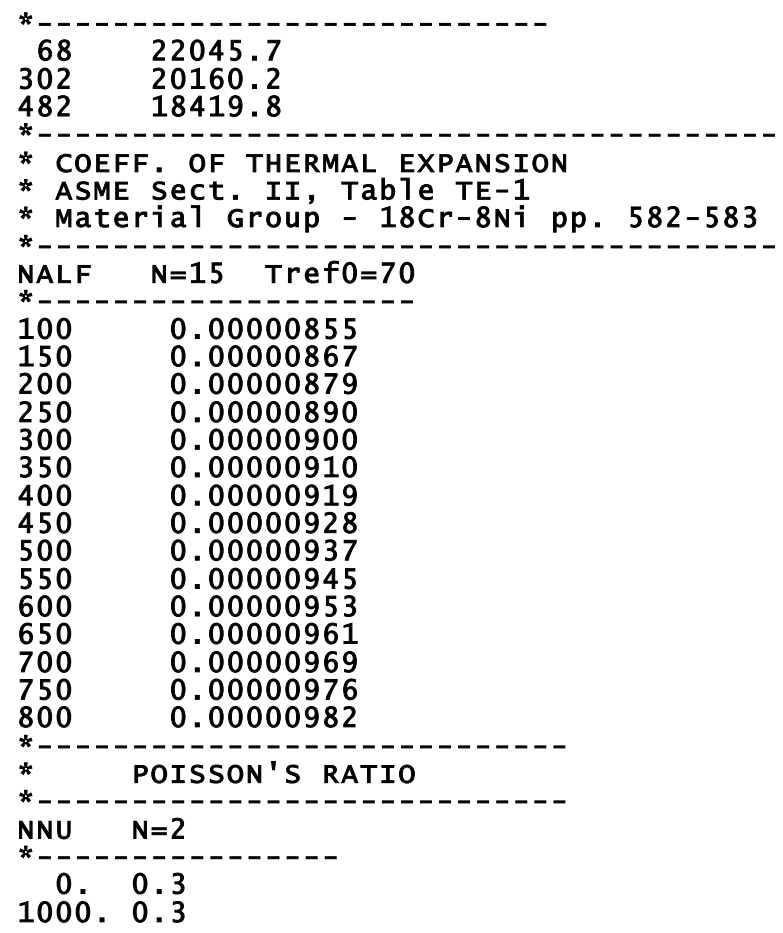

The following sources were consulted to develop the temperature-dependent tables shown above:

\section{Base Steel}

ASME Boiler and Pressure Vessel Code - Sect. II., Part D: Properties (1998)

thermal conductivity - Table TCD - Material Group A - p. 592

thermal diffusivity - Table TCD - Material Group A - p. 592

Young's Modulus of Elasticity - Table TM-1 - Material Group A - p. 606

Coefficient of Expansion - Table TE-1 - Material Group D - p. 580-581

Density $=489 \mathrm{lbm} / \mathrm{ft}^{3}$

\section{Cladding}

ASME Boiler and Pressure Vessel Code - Sect. II., Part D: Properties (1998) thermal conductivity - Table TCD - High Alloy Steels - p. 598

thermal diffusivity - Table TCD - High Alloy Steels - p. 598

Young's Modulus of Elasticity - NESC II Project - Final Report - p. 35

Coefficient of Expansion - Table TE-1 - High Chrome Steels - p. 582-583

Density $=489 \mathrm{lbm} / \mathrm{ft}^{3}$

\section{Record 4 - SFRE}

Record 4 inputs the thermal stress-free temperature for both the base and cladding in ${ }^{\circ} \mathrm{F}$. In addition, crack-face pressure loading on surface-breaking flaws can be applied with $\mathbf{C F P}=\mathbf{1}$. If $\mathbf{C F P}=\mathbf{0}$, then no crack-face pressure loading will be applied.

\section{EXAMPLE}

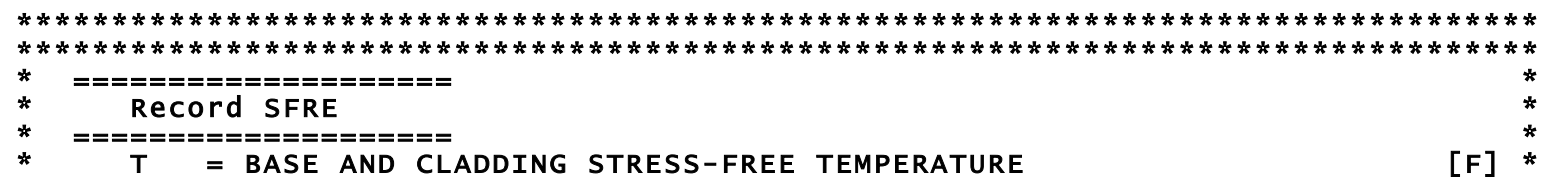


* CFP = crack-face pressure loading flag

* $\quad$ CFP $=0==>$ no crack-face pressure loading

* CFP $=1==$ crack-face pressure loading applied

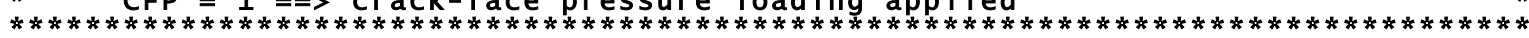

SFRE T=488 CFP=1

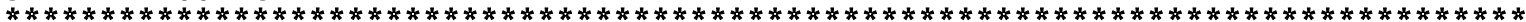

\section{Records 5 and 6 - RESA and RESC}

Records 5 and 6 set weld residual stress flags, NRAX and NRCR, for axial and circumferential welds, respectively. If NRAX or NRCR are set to a value of 101, then weld residual stresses will be included in the FAVLoad output file. If NRAX or NRCR are set to a value of 0 , then weld residual stresses will not be included in the FAVLoad output file.

\section{EXAMPLE}

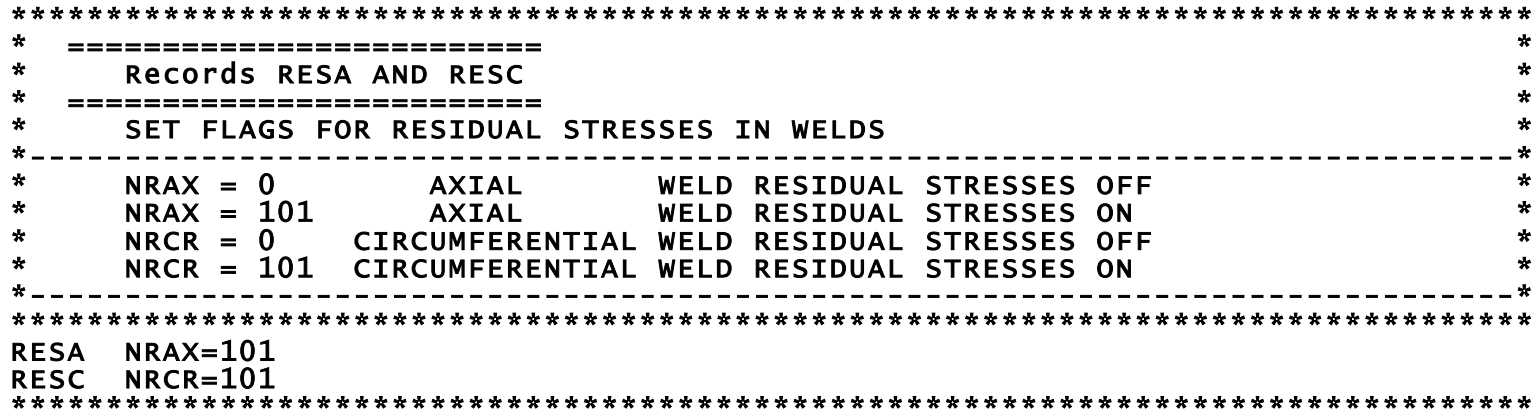

\section{Record 7 - TIME}

Record 7 inputs the total elapsed time, TIME, in minutes for which the transient analysis is to be performed and the time increment, DT, also in minutes, to be used in the time integration in FAVPFM. Internally, the FAVLoad module uses a constant time step of 1.0 second to perform finiteelement through-wall heat-conduction analyses (1D axisymmetric).

\section{EXAMPLE}

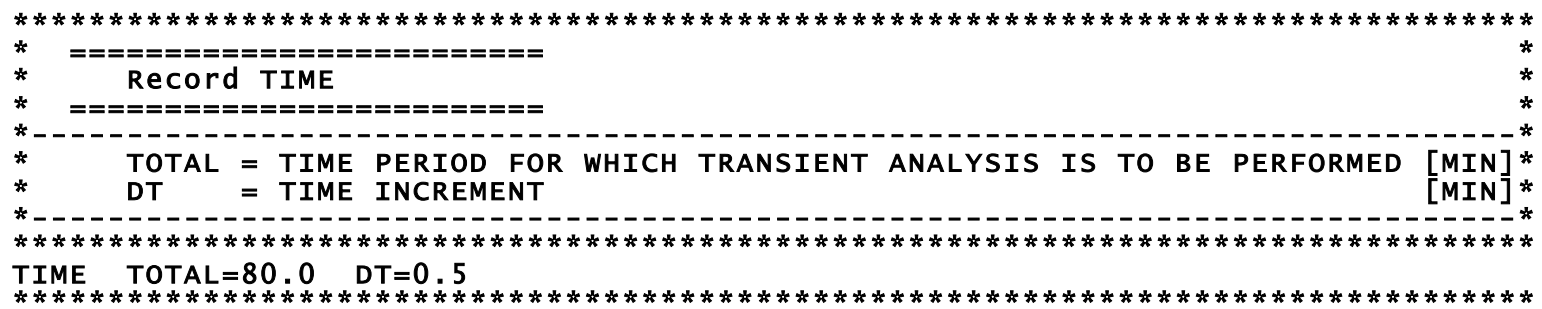

DT is the time-step size for which load results (temperatures, stresses, etc.) are saved during execution of the FAVLoad module; therefore, DT is the time-step size that will be used for all fracture analyses in subsequent FAVPFM executions. Some testing with different values of DT is typically necessary to insure that a sufficiently small value is used that will capture the critical characteristics of the transients under study. Note that there is no internal limit to the size of the time step; however, the computational time required to perform a PFM analysis is inversely proportional to DT. 


\section{Record 8 - NPRA}

Record 8 inputs the number of thermal-hydraulic transients, NTRAN, to be defined for this case. The following Records 9 through 12 should be repeated for each of the NTRAN transients to be defined.

\section{EXAMPLE}

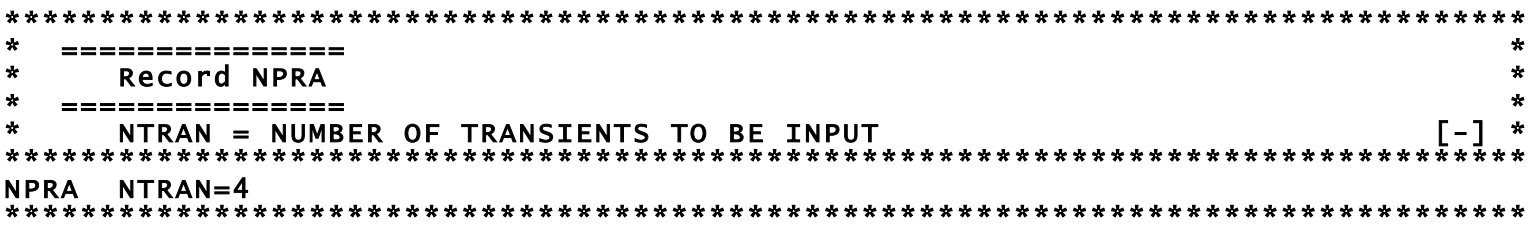

\section{Record 9 - TRAN}

Record 9 provides a mechanism for cross-indexing the internal FAVOR transient numbering system with the initiating-event sequence numbering system used in the thermal-hydraulic analyses that were performed to develop input to FAVOR. The internal FAVOR transient number, ITRAN, is linked with the thermal-hydraulic initiating-event sequence number, ISEQ, with this record. Whereas, the value of ITRAN will depend upon the arbitrary ordering of transients in the FAVLoad transient input stack, the value of ISEQ is a unique identifier for each transient. ITRAN begins with 1 and is incremented by 1 up to NTRAN transients.

\section{EXAMPLE}

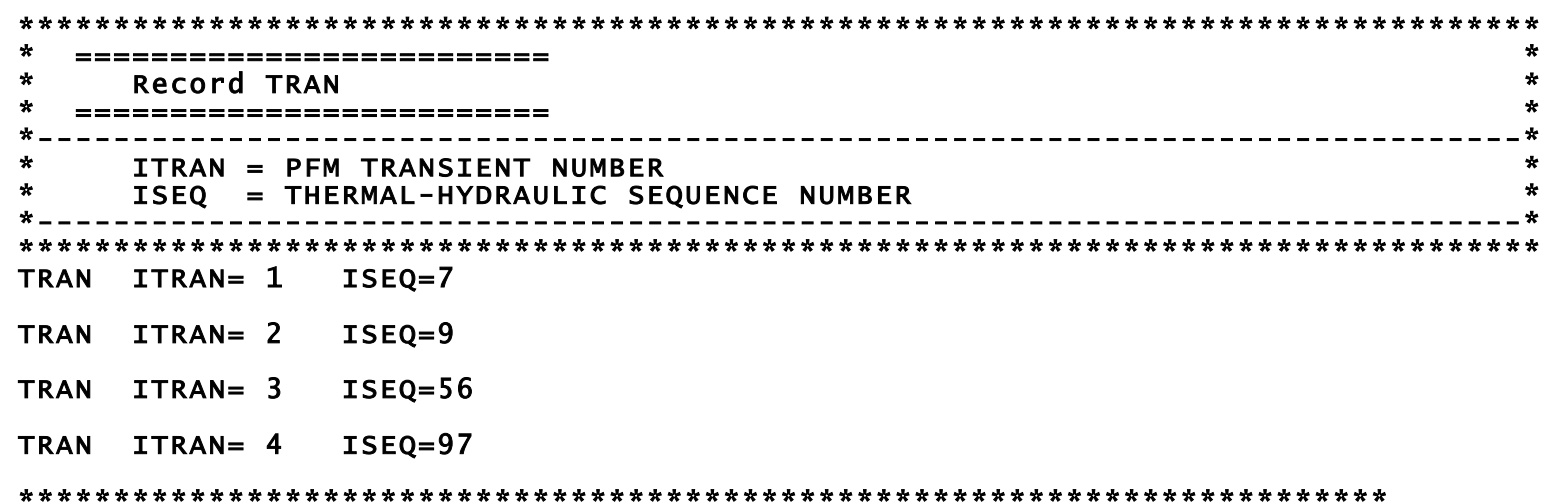

\section{Record 10 - NHTH}

Record 10 inputs the time history table for the convective film coefficient boundary conditions. There are NC data pairs of time, $t$, in minutes and film coefficient, $h$, in Btu/hr- $-\mathrm{ft}^{2}-{ }^{\circ} \mathrm{F}$ entered following the NHTH keyword record line. The number of data pairs is limited only by the memory capacity of the computer. The film coefficient, $h(t)$, is used in imposing a Robin forced-convection boundary condition at the inner vessel wall, $R_{i}$, defined by,

$$
q(R, t)=h(t)\left[T_{\infty}(t)-T_{\text {wall }}(R, t)\right] \text { for } R=R_{i}, t \geq 0
$$

where $q(R, t)$ is the heat flux in Btu/hr-ft ${ }^{2}, T_{\infty}(t)$ is the coolant temperature near the RPV wall in ${ }^{\circ} \mathrm{F}$, and $T_{\text {wall }}(R, t)$ is the wall temperature in ${ }^{\circ} \mathrm{F}$.

\section{EXAMPLE}

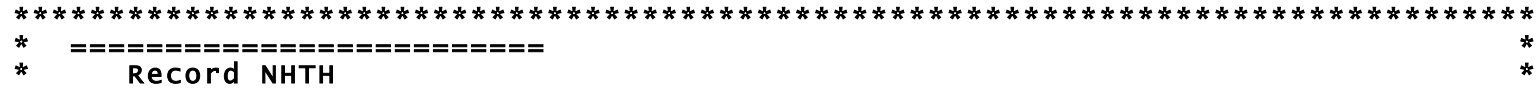




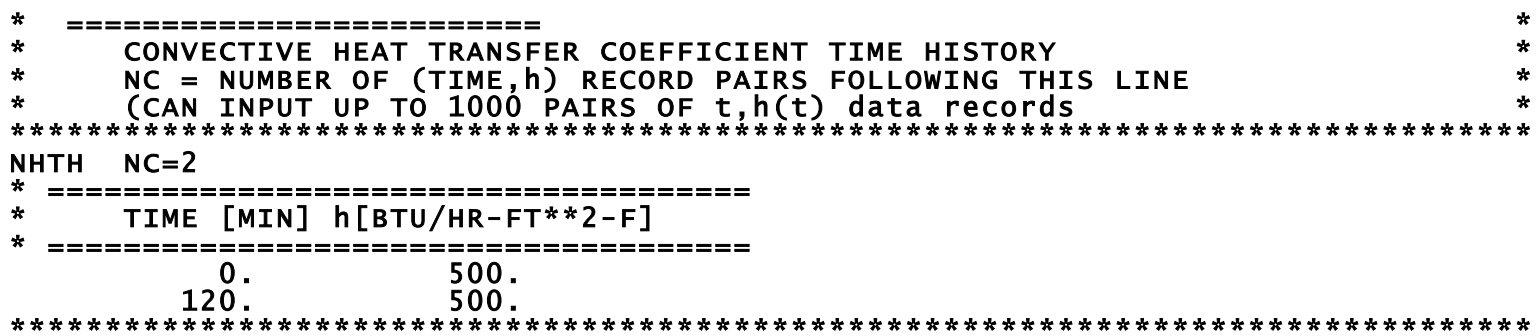

\section{Record 11 - NTTH}

Record 11 inputs the time history definition for the coolant temperature, $T_{\infty}(t)$, which is applied in the Robin boundary condition discussed above. The time history can take two forms depending on the value of the NT parameter. If NT is equal to an integer other than 101, then an ordered table with NT lines of time, $t$, in minutes and temperature, $T$, in ${ }^{\circ} \mathrm{F}$ data pairs will follow the NTTH keyword record. The number of data pairs is limited only by the memory capacity of the computer. If $\mathbf{N T}=101$, then a stylized exponentially decaying time history will be used where the parameters are the initial coolant temperature, TINIT, in ${ }^{\circ} \mathrm{F}$, the asymptote for the coolant temperature, TFINAL, decay curve in ${ }^{\circ} \mathrm{F}$, and the decay time constant, BETA, in minutes ${ }^{-1}$. These parameters define the time history of the coolant temperature by the following equation:

$$
T_{\infty}(t)=T_{\infty-F I N A L}+\left(T_{\infty-I N I T}-T_{\infty-F I N A L}\right) \exp (-\beta t)
$$

EXAMPLES

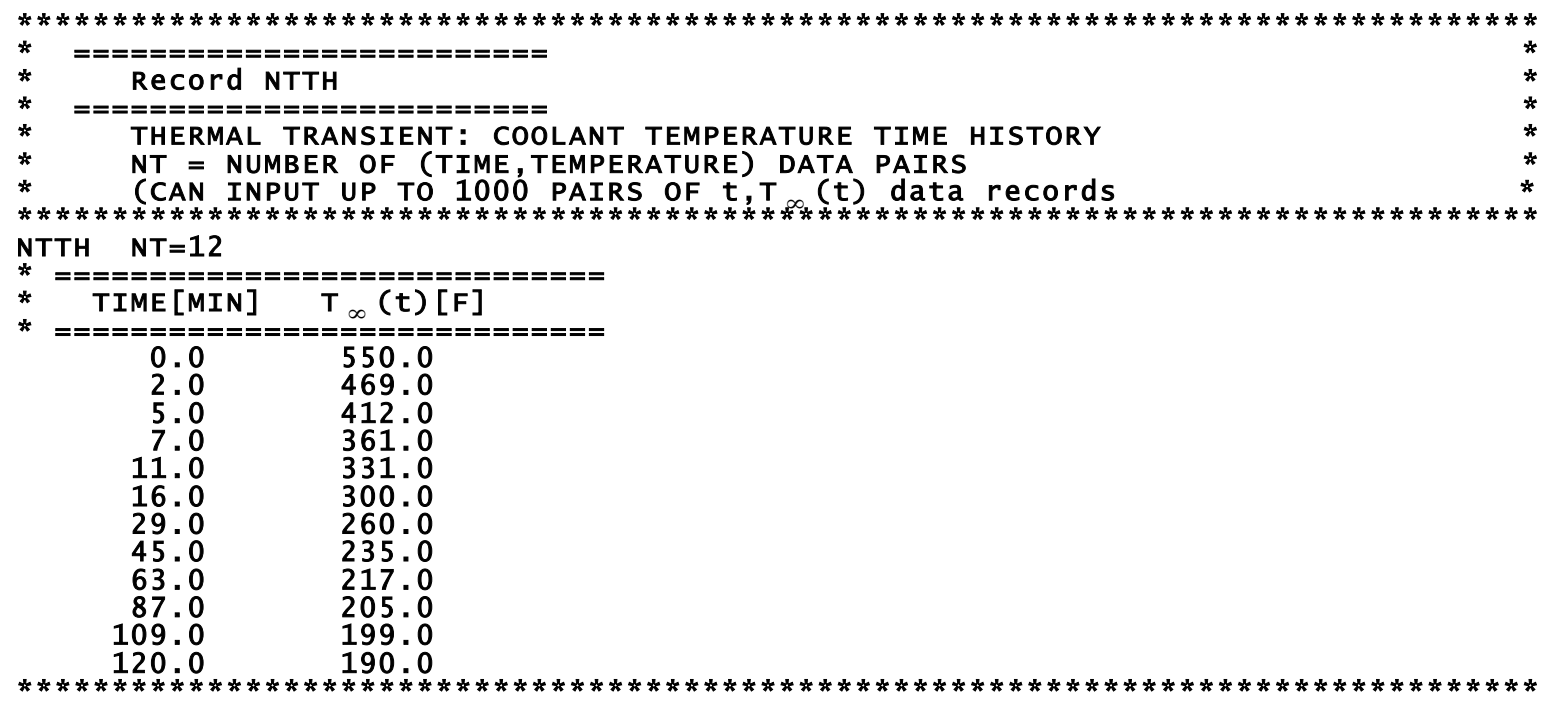

or 


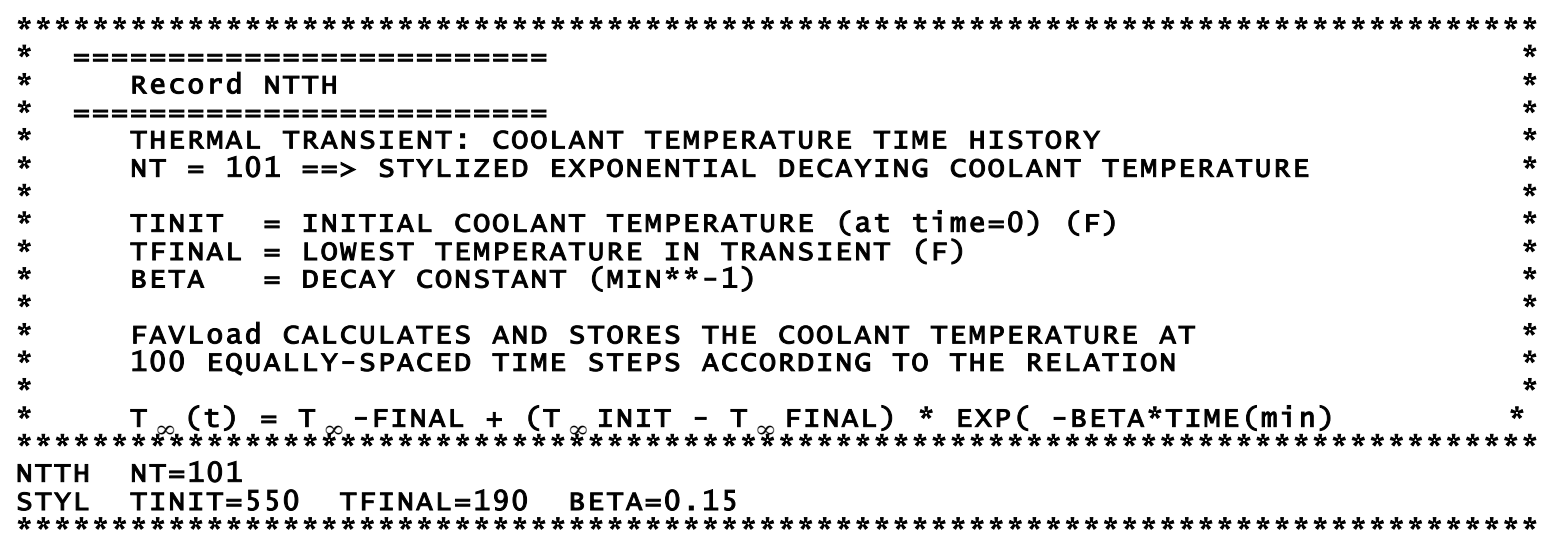

\section{Record 12 - NPTH}

Record 12 inputs the time history table for the internal coolant pressure boundary condition. There are NP data pairs of time, $t$, in minutes and internal coolant pressure, $p$, in kilo-pounds force per square inch (ksi) entered following the NPTH keyword record line. The number of data pairs is limited only by the memory capacity of the computer.

\section{EXAMPLE}

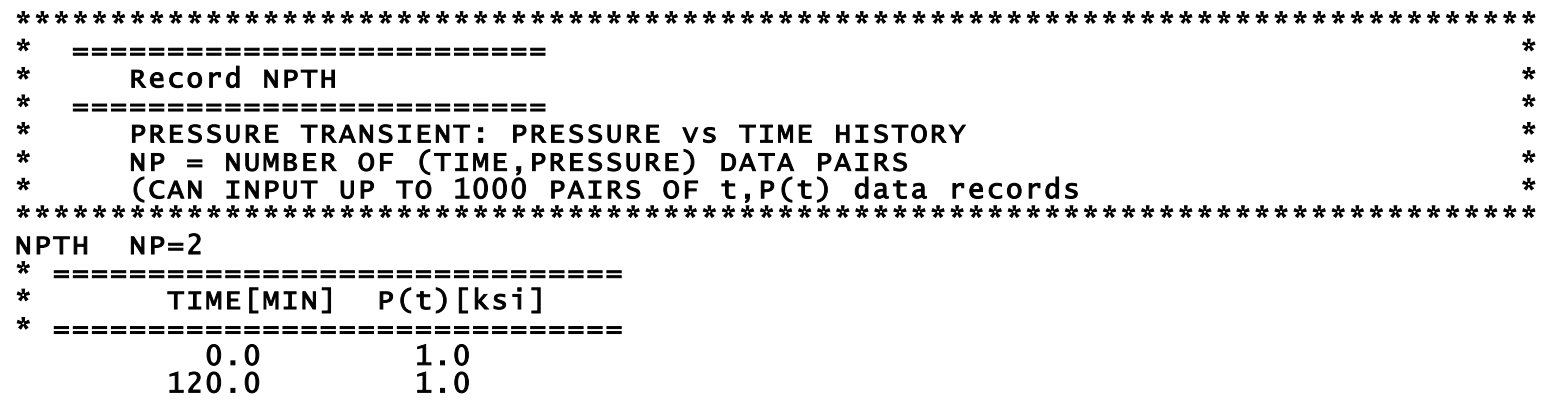

Records 13 through 20 are data obtained from Grizzly.

\section{Record 13 - GNTI}

Record 13 inputs NTIMES_GRI which is the number of time steps available from the Grizzly simulation.

\section{Record 14 - GNME}

Record 14 inputs NUMNP_GRI which is the number of thru-wall mesh points available from the Grizzly simulation.

\section{Record 15 - Time Discretization from Grizzly}

Record 15 inputs NTIMES_GRI data lines of (time step[-], time[minutes]) ordered pairs used in the Grizzly simulation. 


\section{Record 16 - Thru-Wall Mesh Discretization from Grizzly}

Record 16 inputs NUMNP_GRI data lines of mesh points (as measured from the inner RPV wall) used in the Grizzly simulation.

\section{Record 17 - Internal Pressures from Grizzly}

Record 17 inputs NTIMES_GRI data lines of internal pressures available from the Grizzly simulation.

\section{Record 18 - Time-dependent Temperature Profiles from Grizzly}

Record 18 inputs NTIMES_GRI x NUMNP_GRI data lines of time-dependent thru-wall temperature profiles available from the Grizzly simulation.

\section{Record 19 - Time-dependent Hoop Stress Profiles from Grizzly}

Record 19 inputs NTIMES_GRI x NUMNP_GRI data lines of time-dependent thru-wall hoop stress profiles available from the Grizzly simulation.

\section{Record 20 - Time-dependent Axial Stress Profiles from Grizzly}

Record 20 inputs NTIMES_GRI x NUMNP_GRI data lines of time-dependent thru-wall axial stress profiles available from the Grizzly simulation.

\subsection{Grizzly/FAVOR Interface Output Files}

The Grizzly/FAVOR Interface application creates two output ASCII text files:

(1) the load-definition file (a user-defined filename at the time of execution) that will be input to FAVPFM (*.out) and

(2) an *.echo file which provides a date and time stamp of the execution and an echo of the Grizzly/FAVOR Interface input file.

The following gives partial listings of typical Grizzly/FAVOR Interface load-definition and echo files. The name of the Grizzly/FAVOR Interface echo file is constructed from the root of the Grizzly/FAVOR Interface load-definition output file as specified by the user during execution with the ".echo" extension added, e.g., Load1.out $\Rightarrow$ Load1.echo. 


\section{Grizzly/FAVOR Interface Load-Definition Output File}

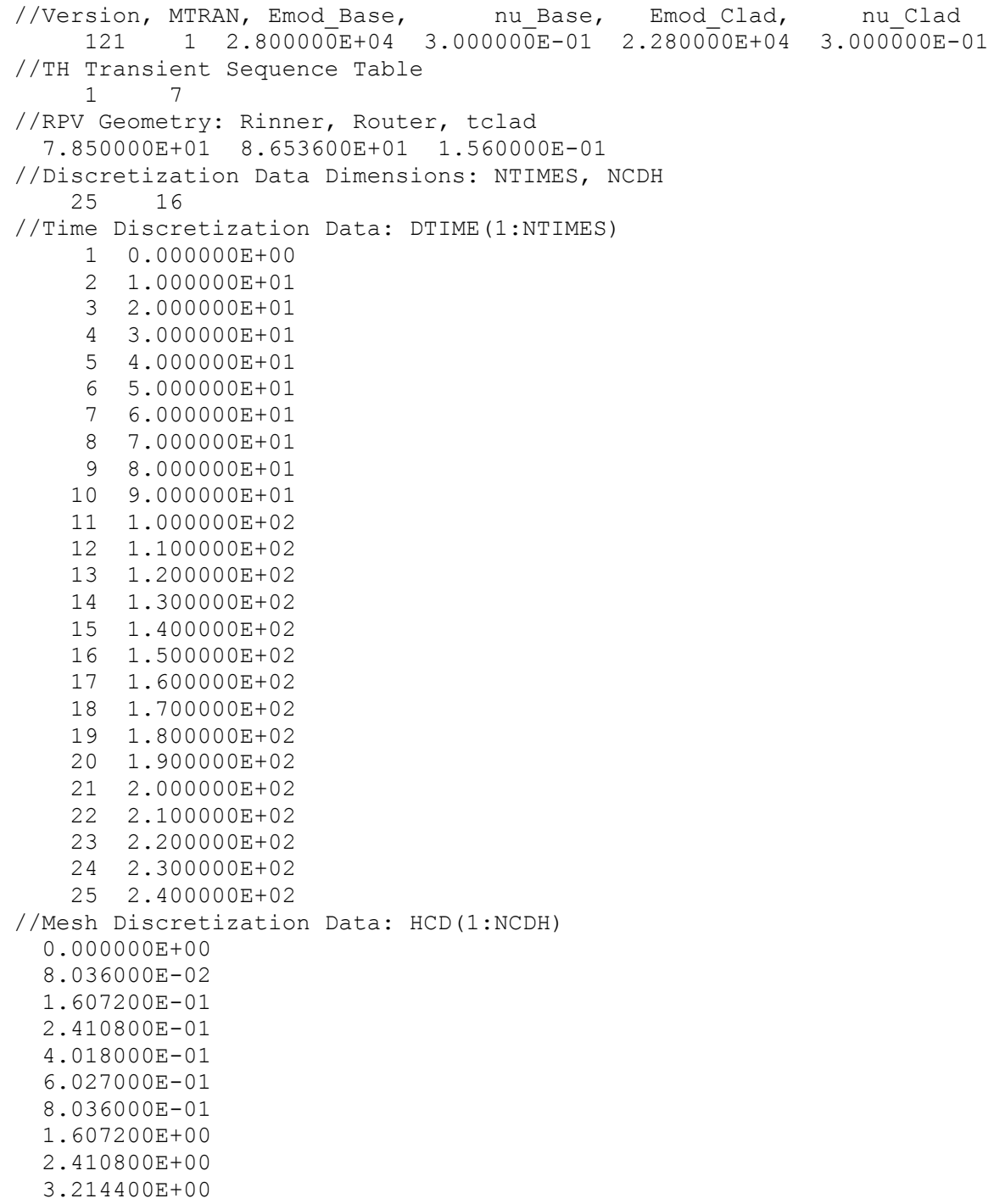




\section{Grizzly/FAVOR Interface Output Echo File}

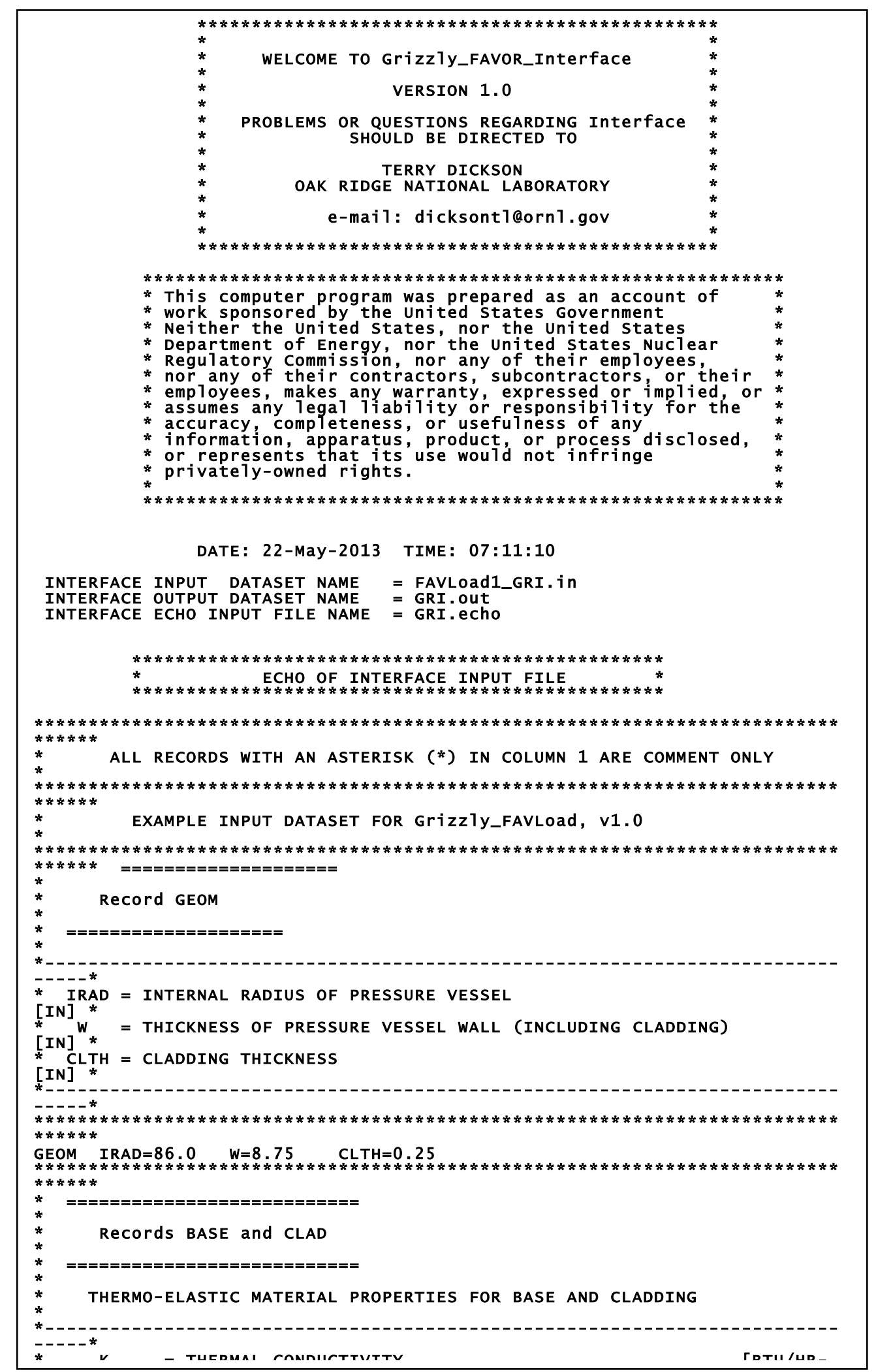




\subsection{Grizzly/FAVOR Interface Software Engineering Metrics}

The Grizzly/FAVOR Interface is written in Fortran 90/95. To track the source code changes, the Grizzly/FAVOR Interface code is being stored in a Subversion repository. As of Subversion's revision 8, tag version 1, the Grizzly/FAVOR Interface code has 5666 Lines of Code. 


\section{VERIFICATION}

\subsection{Initial Benchmarking of FAVOR and Grizzly}

A necessary initial step (in building an interface between Grizzly and FAVOR) is to verify that FAVOR and Grizzly mutually verify each other's solutions for thermal, hoop stress, and axial stress finite element analyses for complex thermal hydraulic loading imposed on the inner surface of the reactor pressure vessel (RPV).

Figure 5 illustrates such a transient. This was transient sequence number 130 postulated for Beaver Valley during the pressurized thermal shock (PTS) re-evaluation. This was one of 61 transients included in the PTS re-evaluation of Beaver Valley. Figure 5 illustrates the coolant temperature and pressure time history boundary conditions that are assumed to be imposed on the inner surface of the RPV. This thermal hydraulic boundary condition was generated by the RELAP5 computer code.

Figure 6 illustrates the probability distribution function (PDF) of the frequency of occurrence (events per reactor operating year) of this particular transient actually occurring. This was generated by the SAPHIRE7 computer code.

The specific description provided for transient sequence number 130 was as follows: reactor turbine trip with one stuck open pressurizer safety relief which recloses at 3000 seconds.

Transient sequence 130 was considered a dominant transient, i.e., it contributed a significant fraction of the total risk for Beaver Valley for all times in the life of the RPV. The primary characteristic of this transient is the re-pressurization that occurs relatively late in the transient after the RPV has cooled down. Transients with this characteristic were found to be the dominant transients for all reactors analyzed in the Pressurized Thermal Shock ReEvaluation.

From Figure 7 through Figure 9 we illustrate that the FAVOR and Grizzly time history solutions for the temperature, axial stress, and hoop stress, respectively, occurring at a specified distance into the RPV wall (measured from the RPV wetted inner surface) are in reasonably good agreement.

The verifications provided in Figure 7 - Figure 9 provided assurance that the objectives illustrated in Figure 1 and Figure 4 have been met.

It should be noted that the analyses represented in Figure 7 to Figure 9 were performed without the stainless steel clad layer. At the time these initial benchmarking calculations were performed, Grizzly did not have the capability to include the stainless steel clad layer. It is anticipated that additional verification will be performed once Grizzly has been modified to have the capability to include clad layer in the model. 


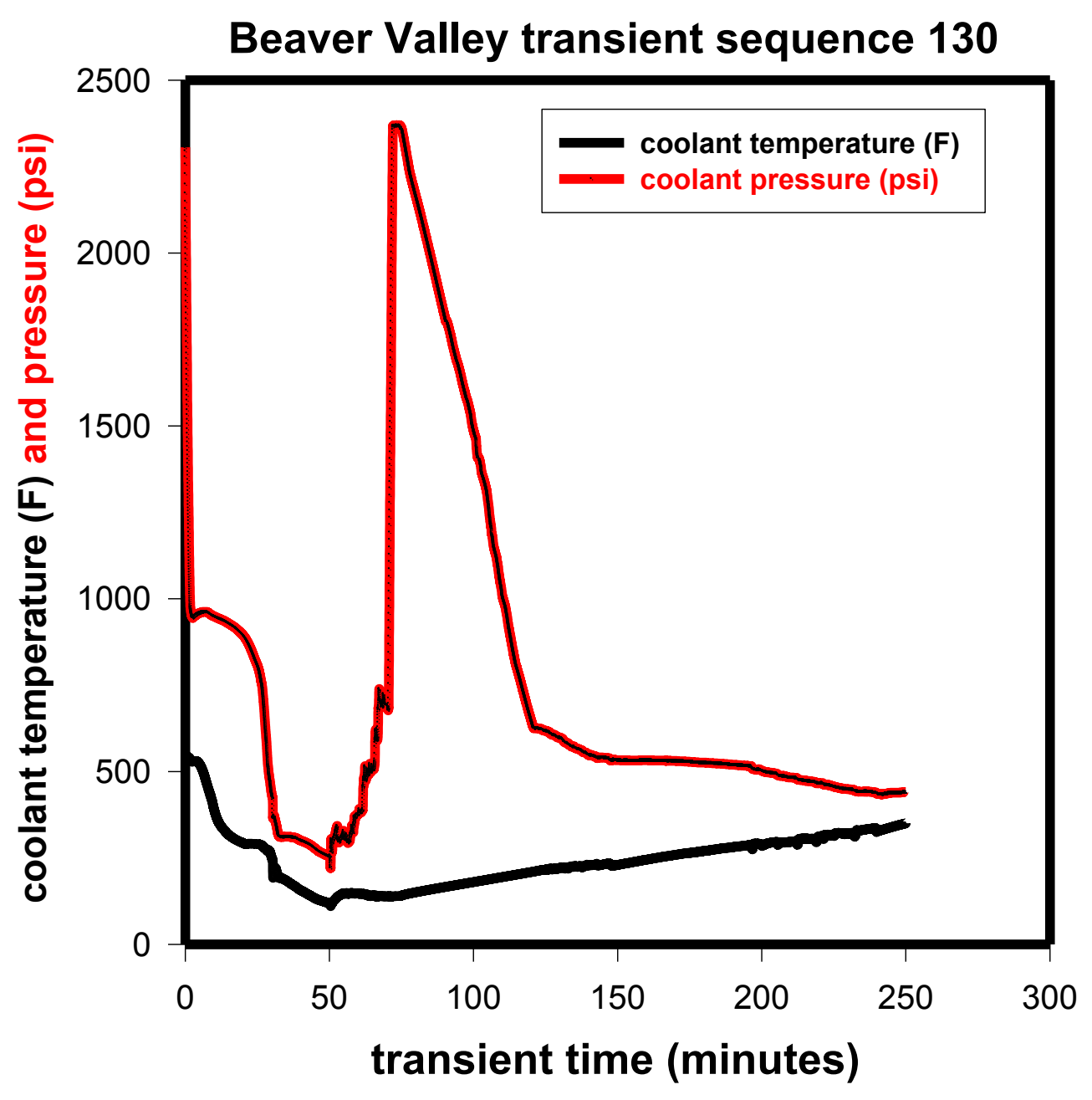

Figure 5 Beaver Valley transient sequence 130 thermal hydraulic boundary condition - sever re-pressurization- is a dominant transient generated by RELAP5. 


\section{probability distribution function (PDF) for frequency of occurrence for postulated Beaver Valley transient 130}

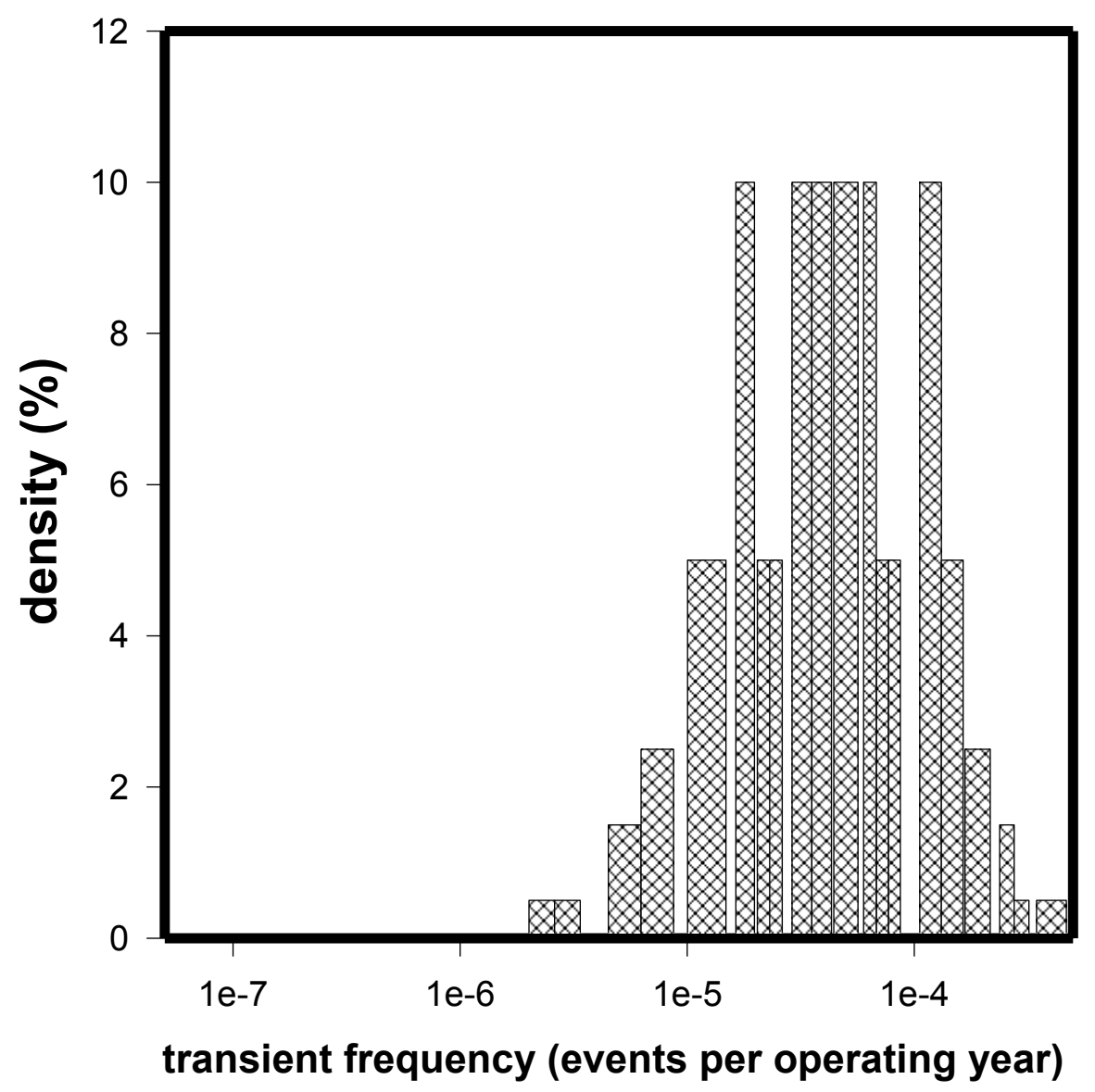

Figure 6 Probability distribution function for the transient frequency for Beaver Valley transient sequence 130. 
Validation of temperature time history for Beaver Valley transient 130

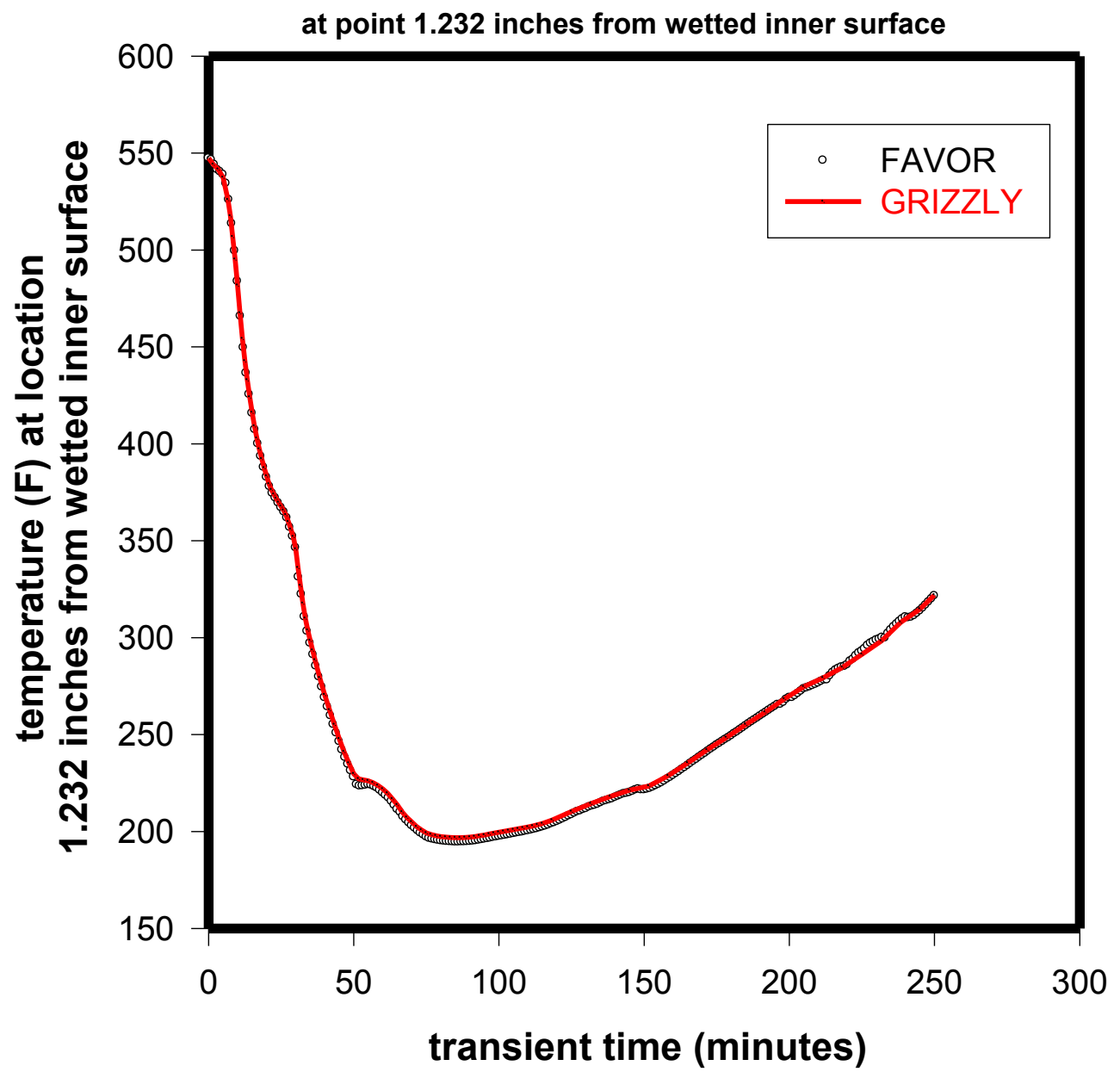

Figure 7 Mutual verification of temperature time history solutions at point in wall thickness for Beaver Valley transient sequence 130. 


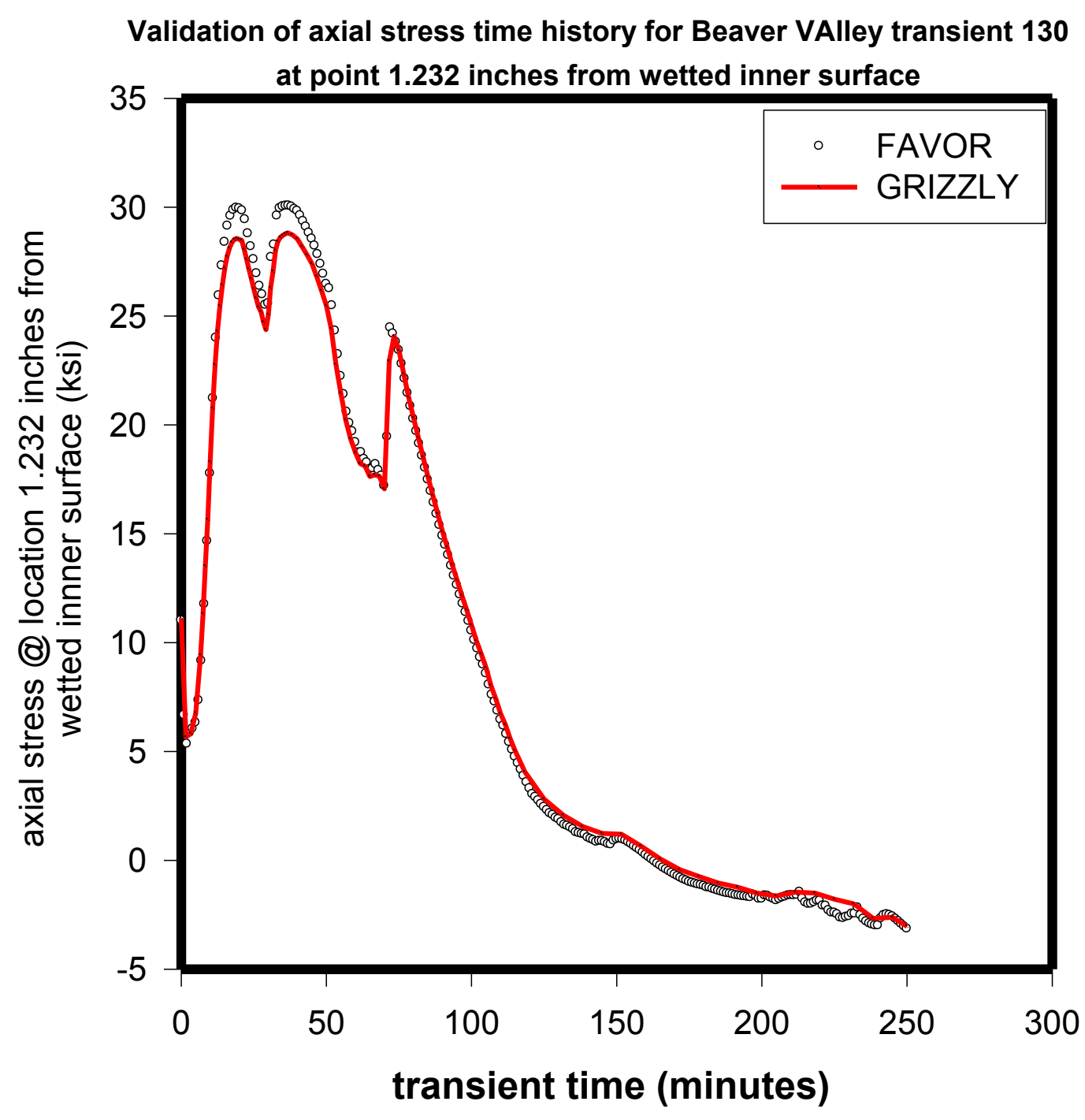

Figure 8 Mutual verification of axial stress time history solutions at point in wall thickness for Beaver Valley transient sequence 130. 


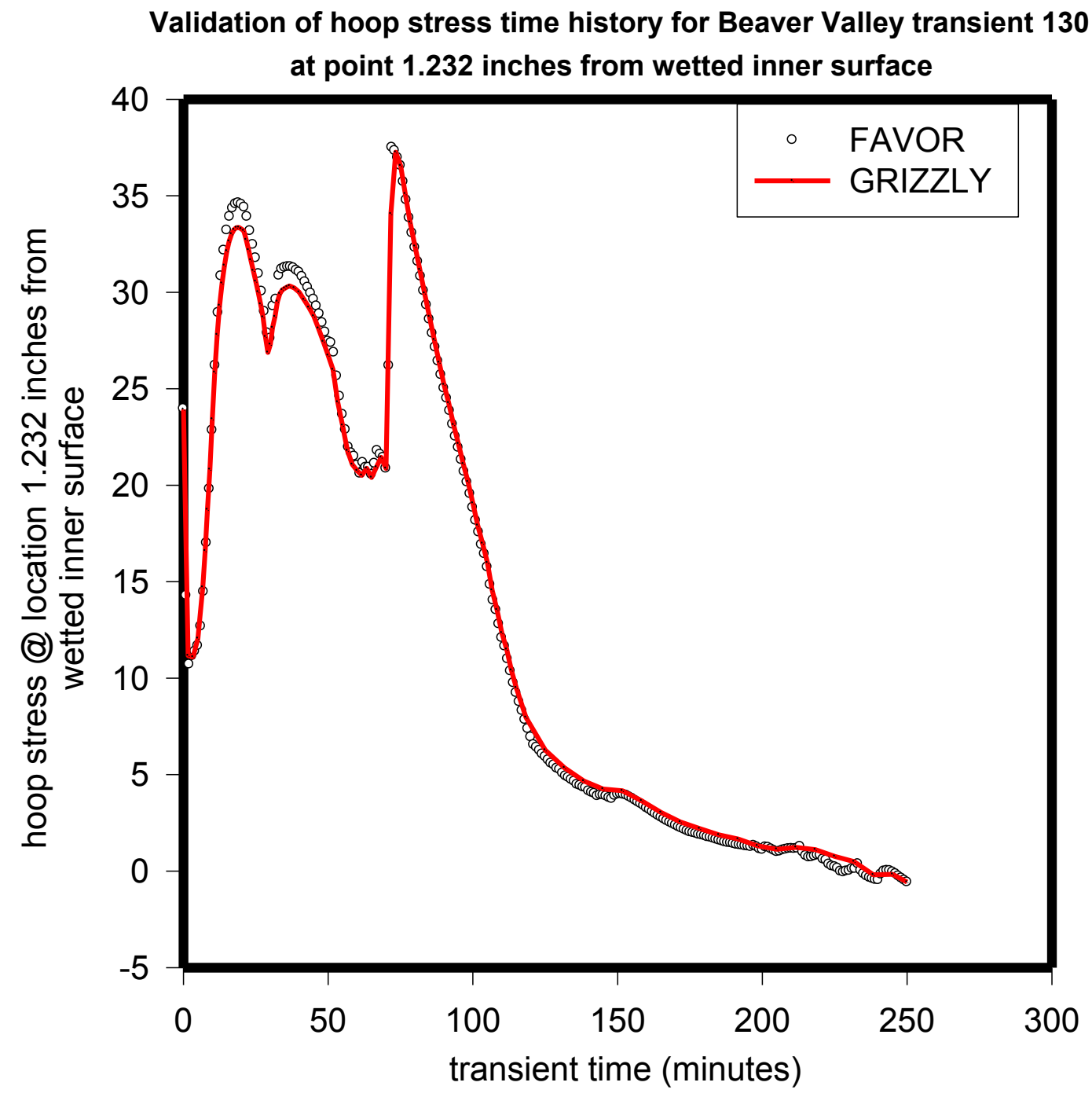

Figure 9 Mutual verification of hoop stress time history solutions at point in wall thickness for Beaver Valley transient sequence 130. 


\subsection{Initial Testing of the Grizzly -FAVOR Interface}

The objective of the Grizzly-FAVOR interface is to map $\sigma_{\text {hoop }}(\mathrm{x}, \mathrm{t}), \sigma_{\text {axial }}(\mathrm{x}, \mathrm{t})$, and $\mathrm{T}(\mathrm{x}, \mathrm{t})$ from any one-dimensional coordinate system to the specific one-dimensional coordinate system (that is output by FAVLOAD) and required as input by FAVPFM as illustrated in Figure 1Figure 1. If this objective is successfully met, the results of Grizzly finite element thermal and stress analyses can be used as input to FAVPFM without requiring any modifications to the FAVPFM. The FAVPFM module is used to perform deterministic and probabilistic fracture mechanics analyses of RPVs subjected to complex thermal hydraulic boundary conditions imposed on their inner surface.

Therefore, for purposes of testing the Grizzly-FAVOR interface, $\sigma_{\text {hoop }}(x, t), \sigma_{\text {axial }}(x, t)$, and $\mathrm{T}(\mathrm{x}, \mathrm{t})$ data generated in any coordinate system (other than the coordinate system that corresponds to the gauss points used in the finite element analyses) can be used as input into the Grizzly-FAVOR interface.

Internally, FAVLOAD and FAVPFM both do mapping of stresses, temperatures, and applied $\mathrm{KI}$ as required. For example, $\sigma_{\text {hoop }}(\mathrm{x}, \mathrm{t}), \sigma_{\text {axial }}(\mathrm{x}, \mathrm{t})$, and $\mathrm{T}(\mathrm{x}, \mathrm{t})$ are mapped (by piecewise cubic spline) from the gauss points used in the thermal and stress finite element analyses to the following 16 locations that correspond to $0.0,0.01,0.02,0.03,0.05,0.075,0.10,0.20$, $0.30,0.40,0.50,0.60,0.70,0.80,0.90$, and 0.95 of the fractional wall thickness. These particular locations correspond to locations for which SIFICs (stress intensity factor influence coefficients) were pre-calculated for infinite length flaws. The SIFICs are used in the calculation of applied stress intensity factors by the method of superposition.

In general, during FAVOR deterministic or probabilistic analyses, if values of $\sigma_{\text {hoop }}(\mathrm{x}, \mathrm{t})$, $\sigma_{\text {axial }}(\mathrm{x}, \mathrm{t})$, and $\mathrm{T}(\mathrm{x}, \mathrm{t})$ at a particular location or for values of $\mathrm{KI}$ for a particular flaw geometry (other than the 16 depths specified above) are required, then the value(s) are generated (mapped) internally by use of the piecewise cubic spline curve fit.

So for purposes of testing the Grizzly-FAVOR interface, $\sigma_{\text {hoop }}(x, t), \sigma_{\text {axial }}(x, t)$, and $T(x, t)$ data generated by FAVOR in any coordinate system (other than the coordinate system that corresponds to the gauss points used in the finite element analyses) can be used as test input into the Grizzly-FAVOR interface .

Figure 10 is an illustration of Beaver Valley transient sequence 007 - a severe cooldown caused by a pipe break.

In Figure 11 through Figure 15, the test case is the time history solutions in a coordinate system used for deterministic reporting, whereas, the FAVOR-Grizzly interface solution is the solutions for $\mathrm{T}(\mathrm{x}, \mathrm{t}), \sigma_{\mathrm{axial}}(\mathrm{x}, \mathrm{t})$, and $\sigma_{\text {hoop }}(\mathrm{x}, \mathrm{t})$, after the test cases solutions have been mapped to the coordinate system required for input into the FAVPFM module.

Similarly, in Figure 16 through Figure 18, the test case is the thru-wall spatial profile solution in a coordinate system used for deterministic reporting, whereas, the FAVOR-Grizzly interface solution is the solution for $\mathrm{T}(\mathrm{x}, \mathrm{t}), \sigma_{\text {axial }}(\mathrm{x}, \mathrm{t})$, and $\sigma_{\text {hoop }}(\mathrm{x}, \mathrm{t})$, after the test cases 
solutions have been mapped to the coordinate system required for input into the FAVPFM module.

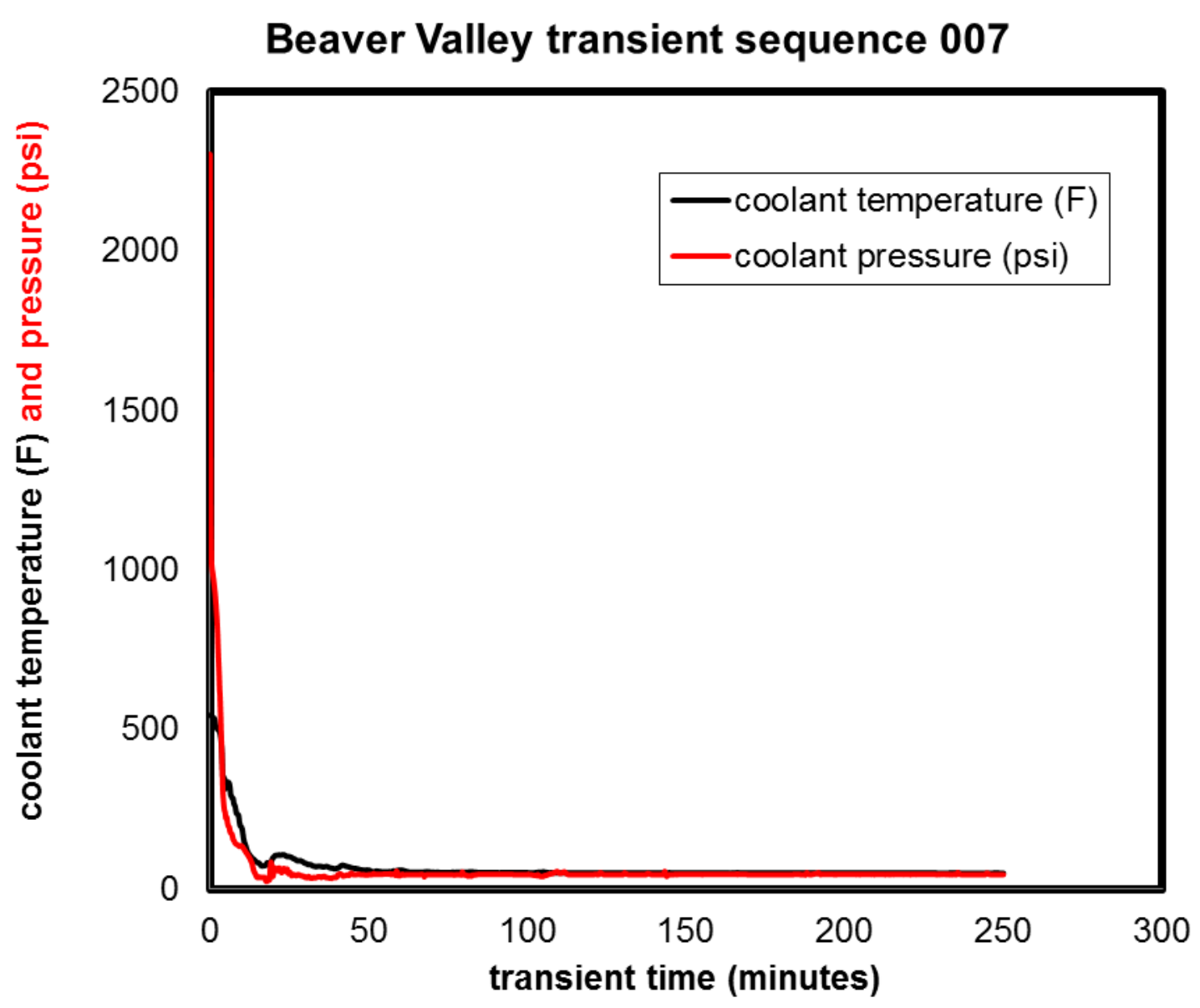

Figure 10 Illustration of Beaver Valley transient sequence 007 - a severe cooldown transient caused by surge line break. 


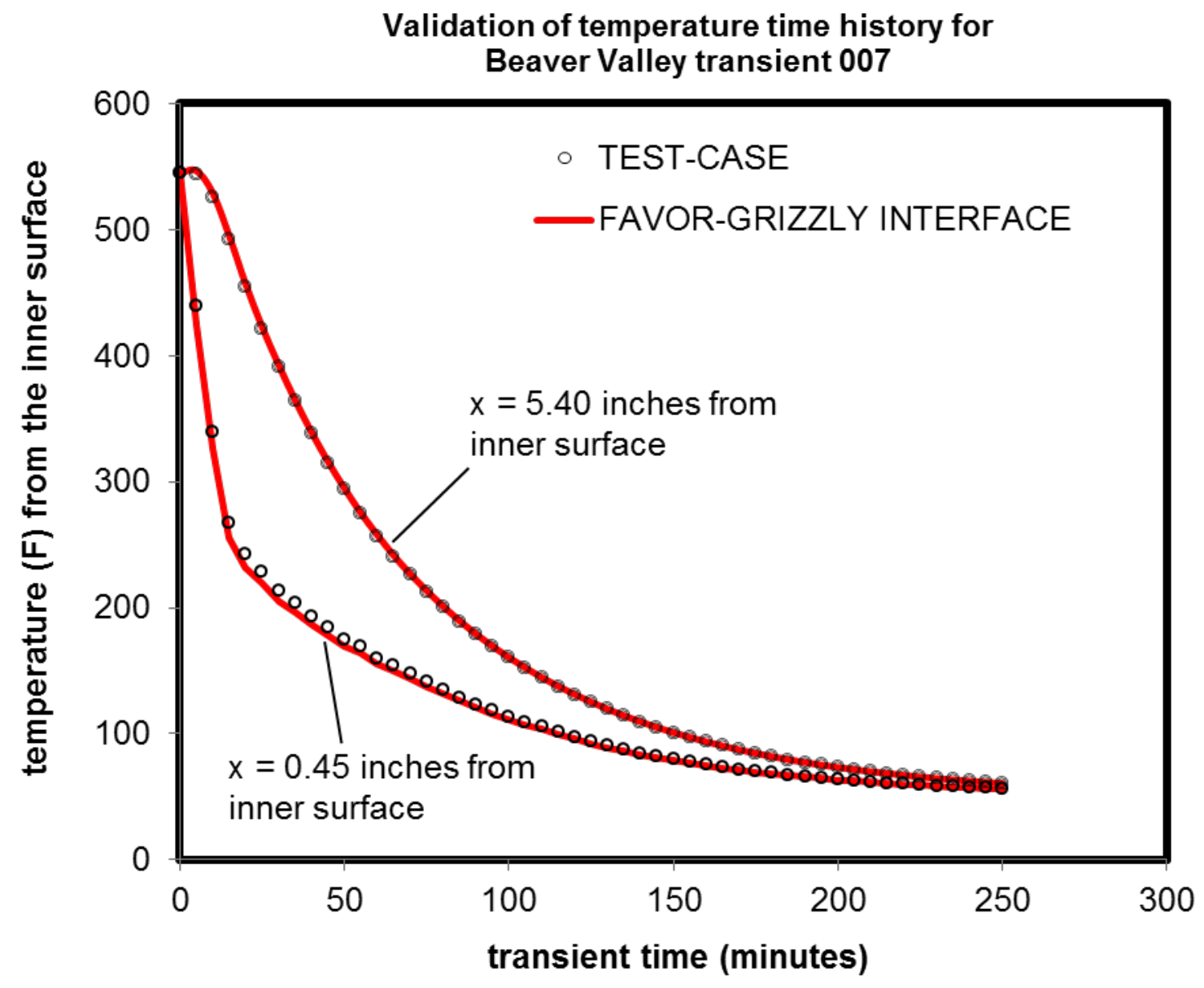

Figure 11 Verification of Grizzly-FAVOR interface for temperature - time history at various locations thru-the-wall thickness 


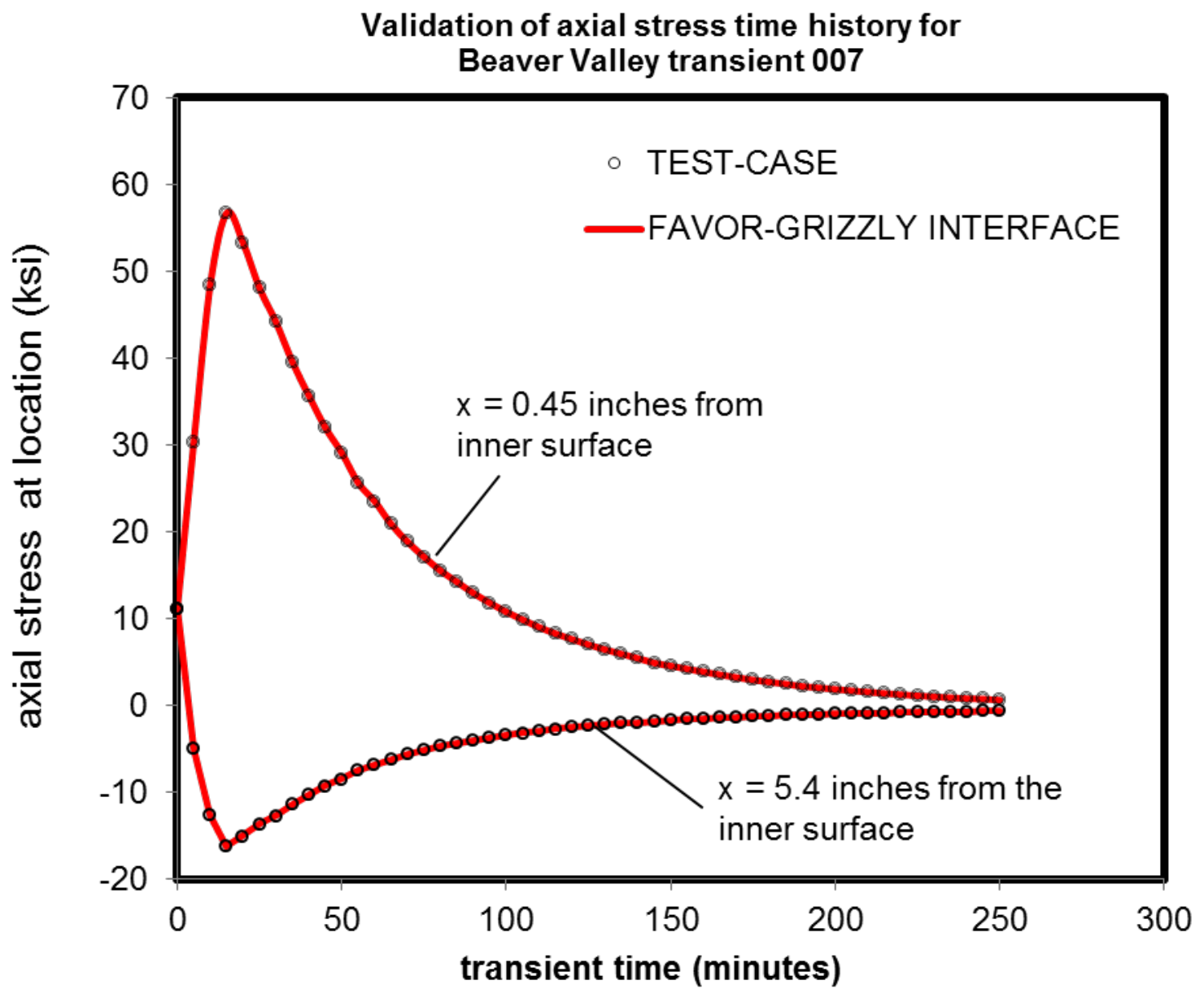

Figure 12 Verification of Grizzly-FAVOR interface for axial stress - time history at various locations thru-the-wall thickness 


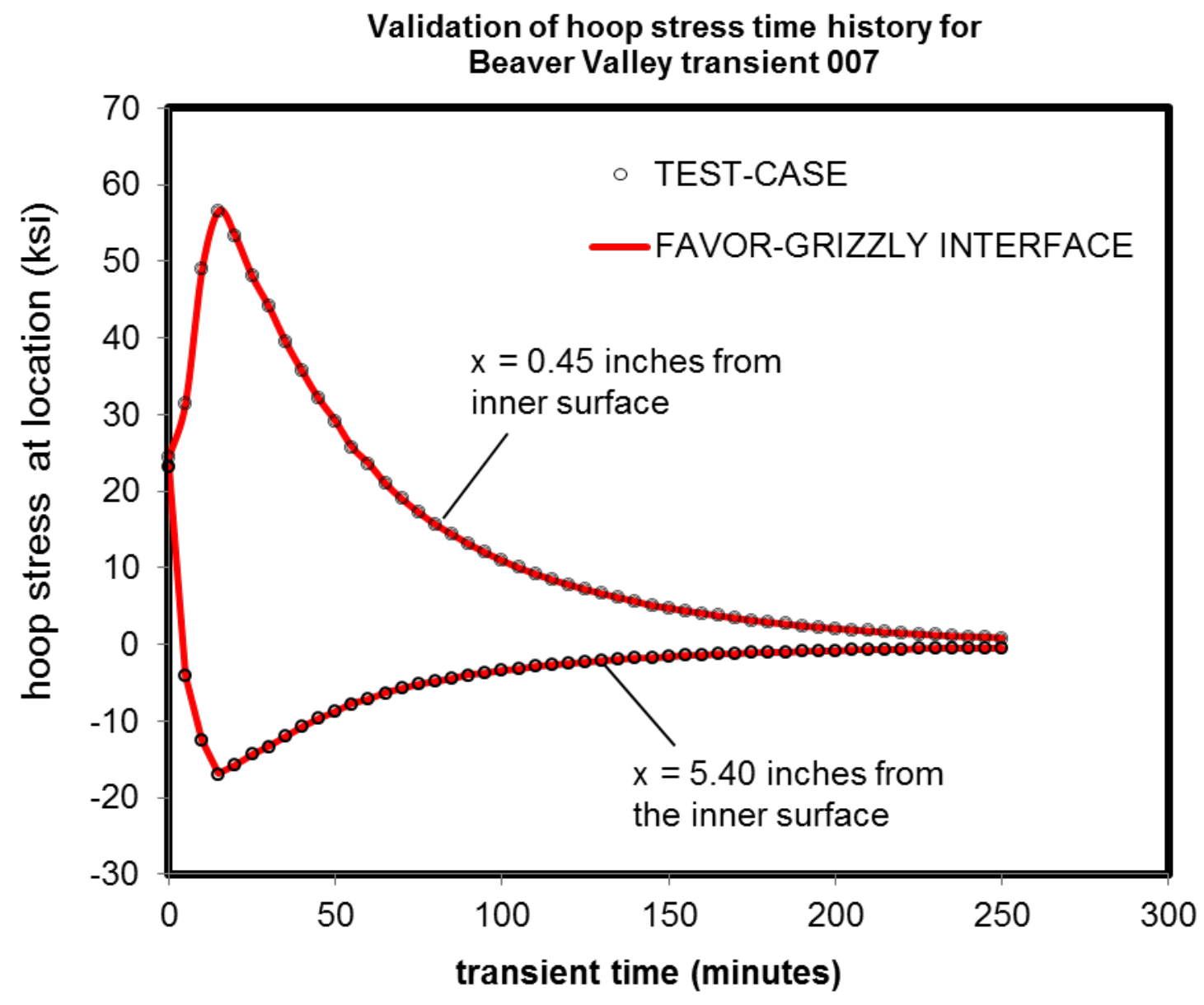

Figure 13 Verification of Grizzly-FAVOR interface for hoop stress-time history at various locations thru-the-wall thickness. 


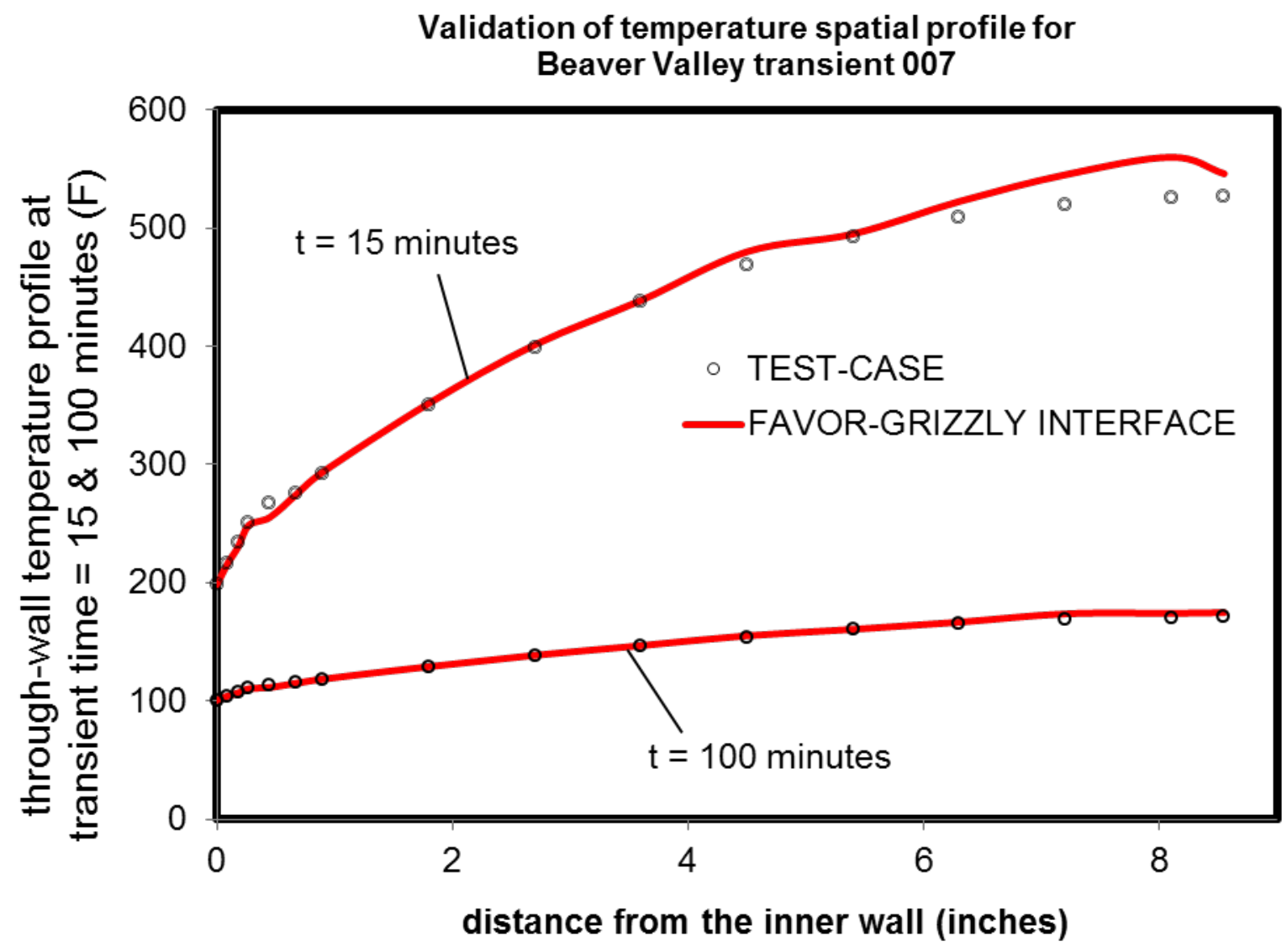

Figure 14 Verification of Grizzly-FAVOR interface for spatial profiles of thru-wall temperatures at different transient times. 
Validation of axial stress profile for Beaver Valley transient 007

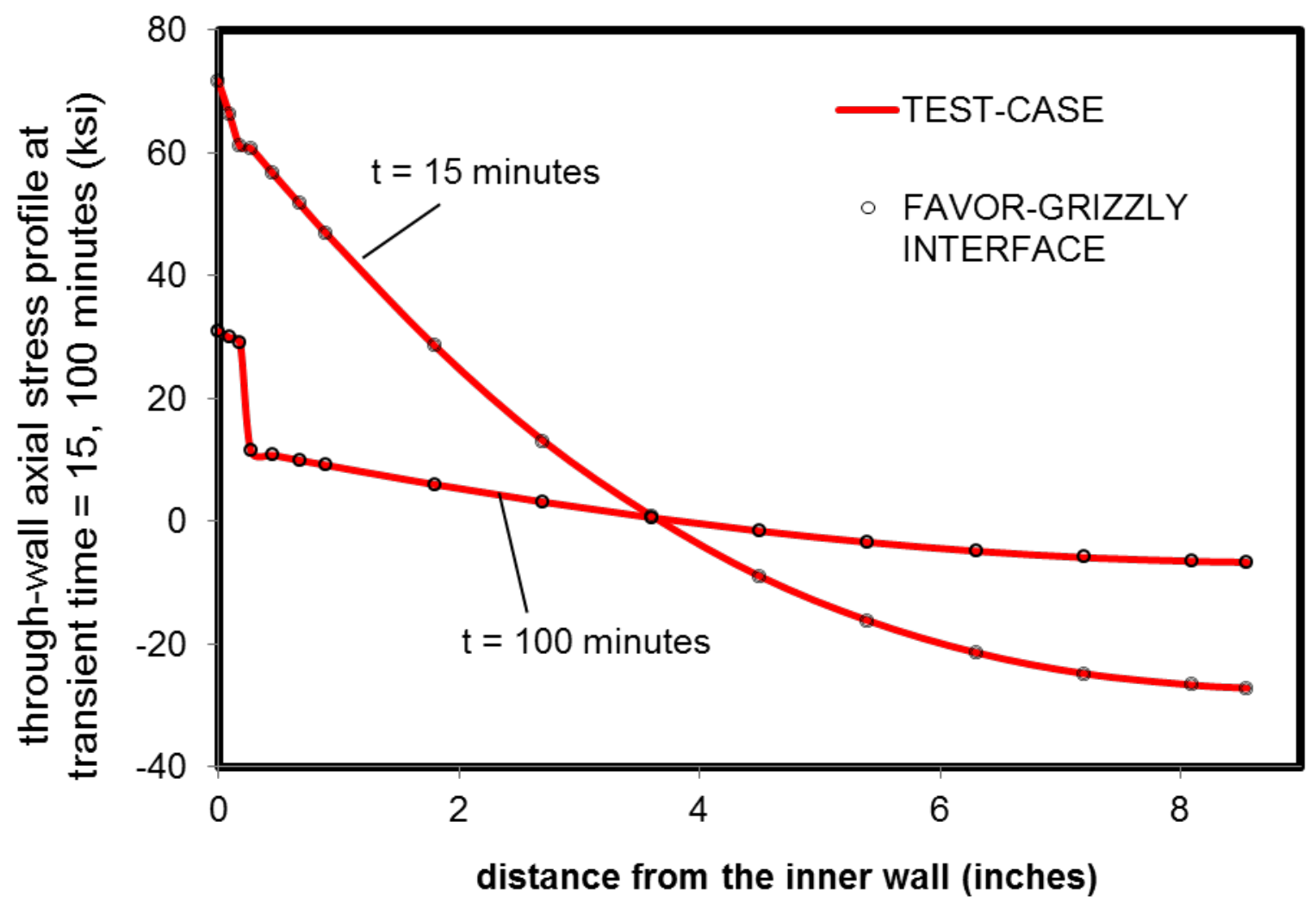

Figure 15 Verification of Grizzly-FAVOR interface for spatial profiles of thru-wall axial stress at different transient times 
Validation of hoop stress profile for Beaver Valley transient 007

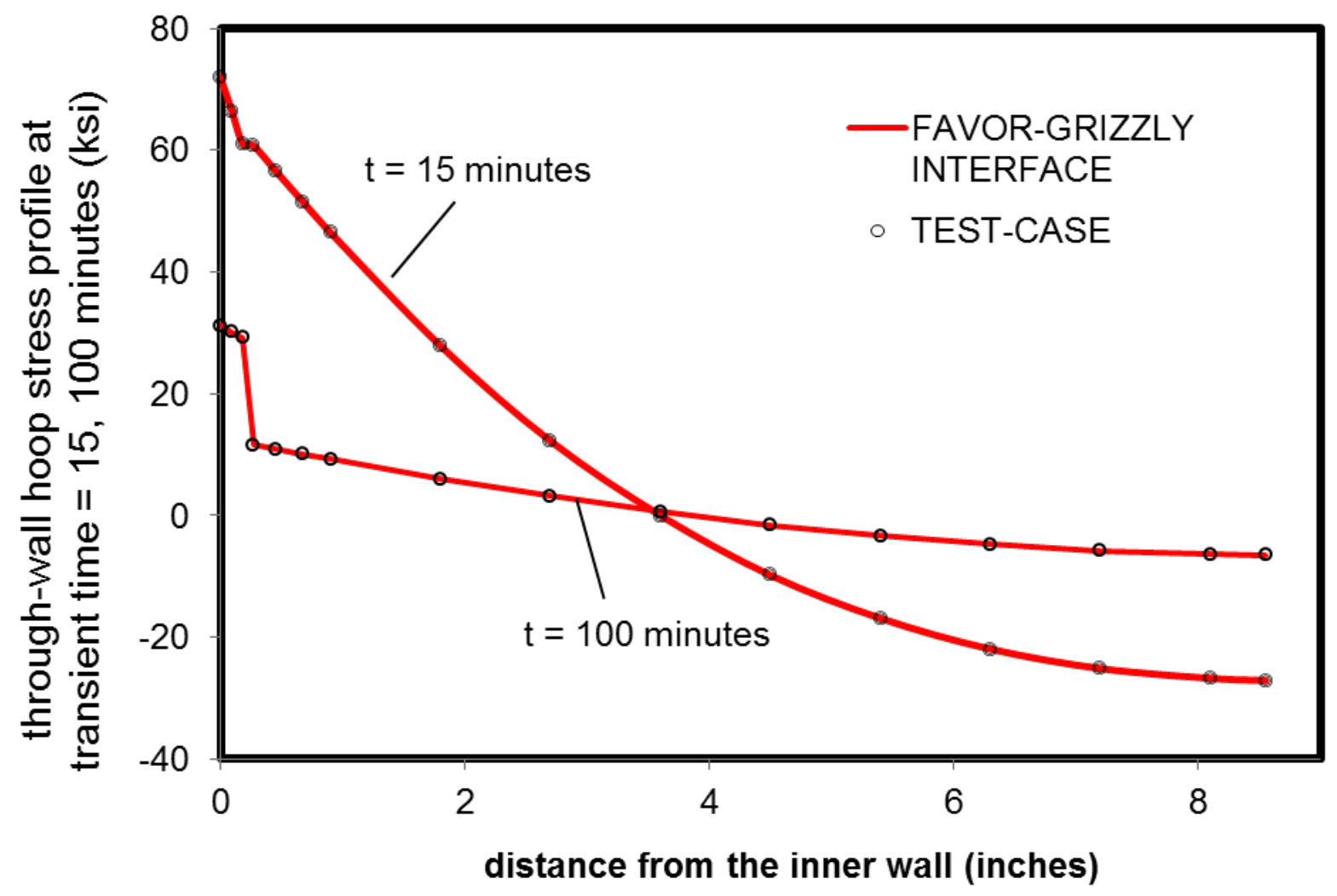

Figure 16 Verification of Grizzly-FAVOR interface for spatial profiles of thru-wall hoop stress at different transient times. 


\section{Grizzly/FAVOR INTERFACE USER GUIDE}

This section describes how to use the Grizzly/FAVOR interface.

\subsection{Grizzly/FAVOR Interface Distribution}

The Grizzly/FAVOR Interface is distributed in a WINZIP archive file along with the executables of FAVOR V12.1 as shown below.

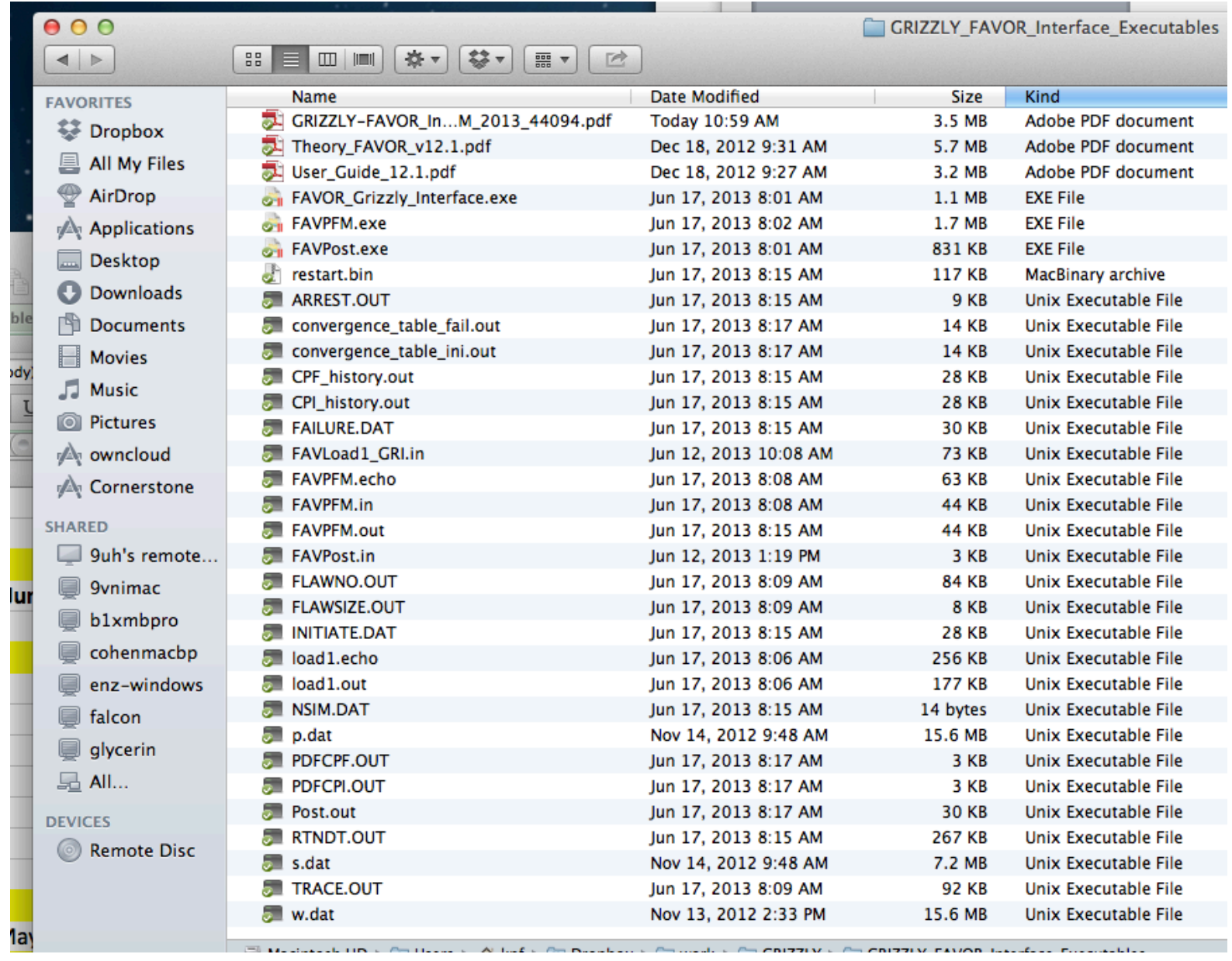

\subsection{Hardware and SOFTWARE Requirements}

The FAVOR/Grizzly Interface code has been run and tested in the following environments:

\section{Hardware:}

- HP Z400 Workstation (x64-based PC) Intel64 Family 6 Model 26 Stepping 5 GenuineIntel $\sim 2368 \mathrm{Mhz}$ )

- HP Z800 Workstation (X86-based PC) x64 Family 6 Model 26 Stepping 5 GenuineIntel $\sim 1729 \mathrm{Mhz}$

\section{Operating Systems:}


- $\quad$ Microsoft Windows 7 Enterprise, version 6.1.7601 Service Pack 1 Build 7601

- Microsoft Windows Vista T Enterprise 6.0.6002 Service Pack 2 Build 6002 


\subsection{Running the Grizzly/FAVOR Interface}

This section describes how to run the Grizzly/FAVOR Interface. On Microsoft Windows operating systems (Windows XP/VISTA/7), the following three modules:

1. FAVOR-Grizzly Interface

2. FAVPFM

\section{FAVPost}

can be started either by double clicking on the executables' icon (named FAVOR_Grizzly Interface.exe, FAVPFM.exe, and FAVPost.exe, respectively) in Windows Explorer, or by opening a $\bar{C}$ ommand Prompt window and typing in the name of the executable at the line prompt as shown in Figure 17a for FAVOR/Grizzly execution.

All input files and executables must reside in the same current working directory. For details on the creation of FAVOR input files see Chapter 2 of ref. [2]. In Figure 17b, the code prompts for the names of the FAVOR/Grizzly input and FAVOR/Grizzly output files. The FAVOR/Grizzly output file will be used as the load-definition input file for the FAVPFM module. Figure 18 shows the messages written to the screen as FAVOR/Grizzly performs its calculations.

Upon creation of the load-definition file by FAVOR/Grizzly, FAVPFM execution can be started by typing "FAVPFM" at the line prompt (see Figure 19). FAVPFM will then prompt the user for the names of six files (see Figure 20):

(1) the FAVPFM input file,

(2) load-definition file output from FAVOR/Grizzly,

(3) a name for the output file to be created by FAVPFM,

(4) the name of the input flaw-characterization file for surface-breaking flaws in weld and plate regions (DEFAULT $=$ S.DAT),

(5) the name of the flaw-characterization file for embedded flaws in weld regions $(\mathrm{DEFAULT}=\mathrm{W} . \mathrm{DAT})$, and

(6) the name of the flaw-characterization file for embedded flaws in plate regions $($ DEFAULT $=$ P.DAT).

The user can accept the default file names for input files (4)-(6) by typing the ENTER key at the prompt. If FAVPFM cannot find the named input files in the current execution directory, it will prompt the user for new file names. If the FAVPFM output file to be created already exists in the current directory, the code will query the user if it should overwrite the file. For RESTART cases, the user will be prompted for the name of a binary restart file created during a previous execution. See Sect. 2.2 of ref. [2], Record 1 - CNT1, for detailed information on the execution of restart cases.

The user may abort the execution at any time by typing a $<$ ctrl $>c$. FAVPFM provides monitoring information during execution by writing the running averages of conditional probabilities of initiation and vessel failure for all of the transients defined in the load file for each RPV trial as shown in Figure 21.

In Figure 22, FAVOR's post-processing module is executed by typing FAVPost at the line prompt. The code will then prompt the user for the names of four files (see Figure 22):

(1) a FAVPost input file,

(2) the file created by the FAVPFM execution that contains the conditional probability of initiation matrix (DEFAULT=INITIATE.DAT), 
(3) the file created by the FAVPFM execution that contains the conditional probability of failure matrix (DEFAULT=FAILURE.DAT), and

(4) the name of the output file to be created by FAVPost that will have the histograms for vessel fracture and failure frequencies.

Again, for files (2) and (3), the user may accept the defaults by typing the RETURN/ENTER key. 
(a)
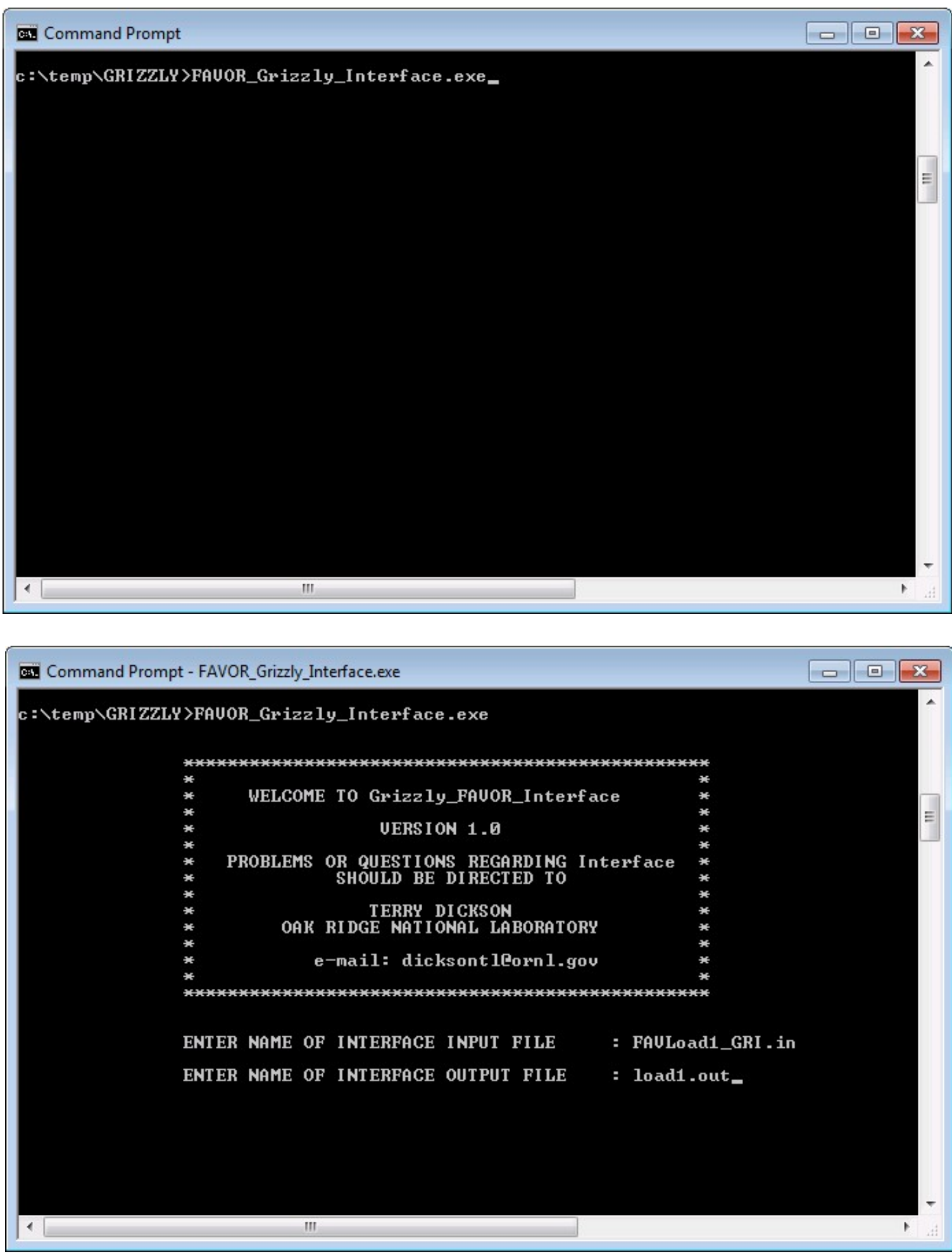

Figure 17. Execution of the Grizzly/FAVOR interface module: (a) type in FAVOR_Grizzly_interface.exe at the line prompt and (b) respond to prompts for the input and output file names 


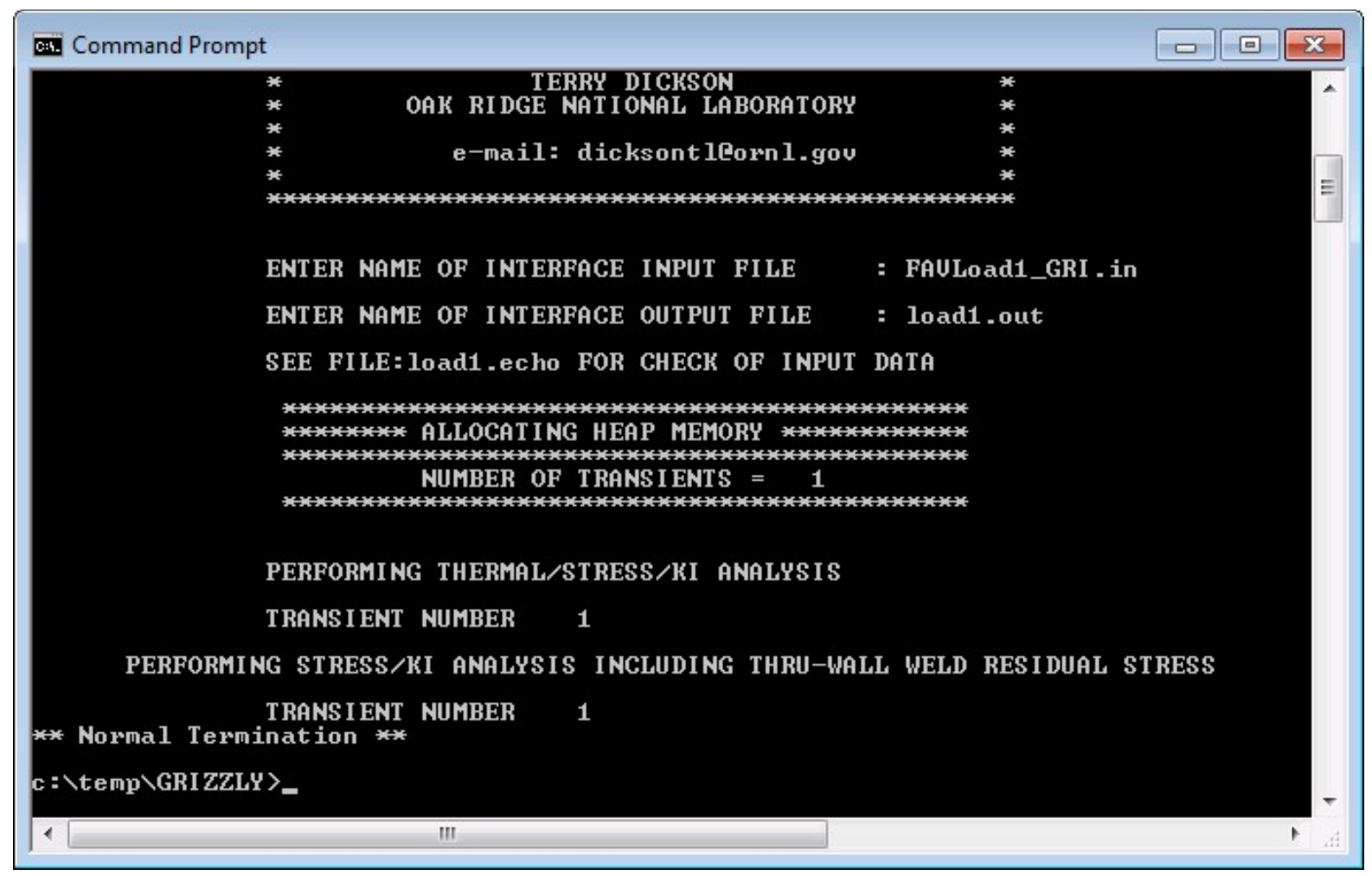

Figure 18. The Grizzly/FAVOR interface calculates thermal, stress, and applied $K_{I}$ loading for all of the transients defined in the input file. 


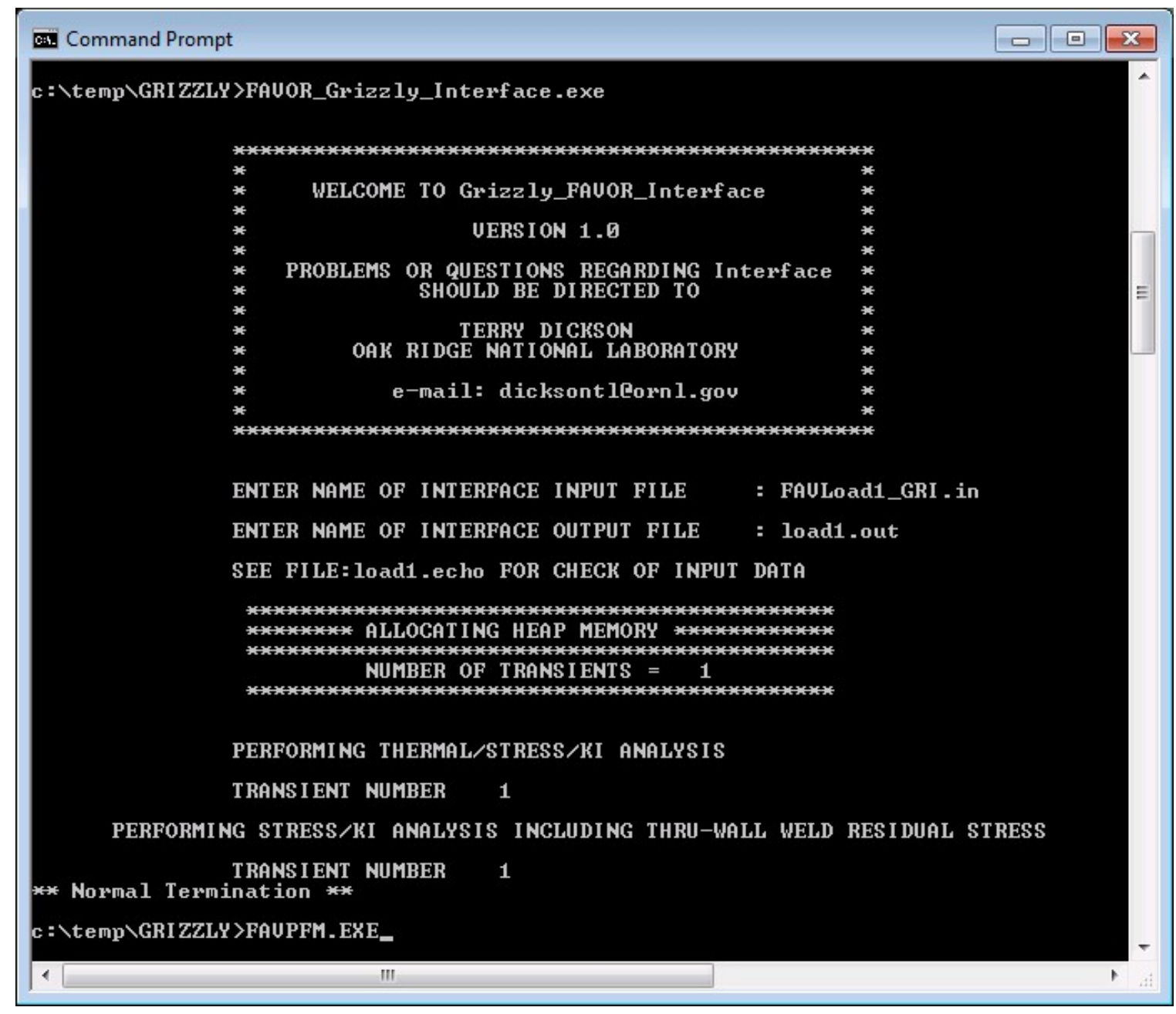

Figure 19. Type FAVPFM.EXE at the Command Prompt to begin execution of the FAVPFM module. 


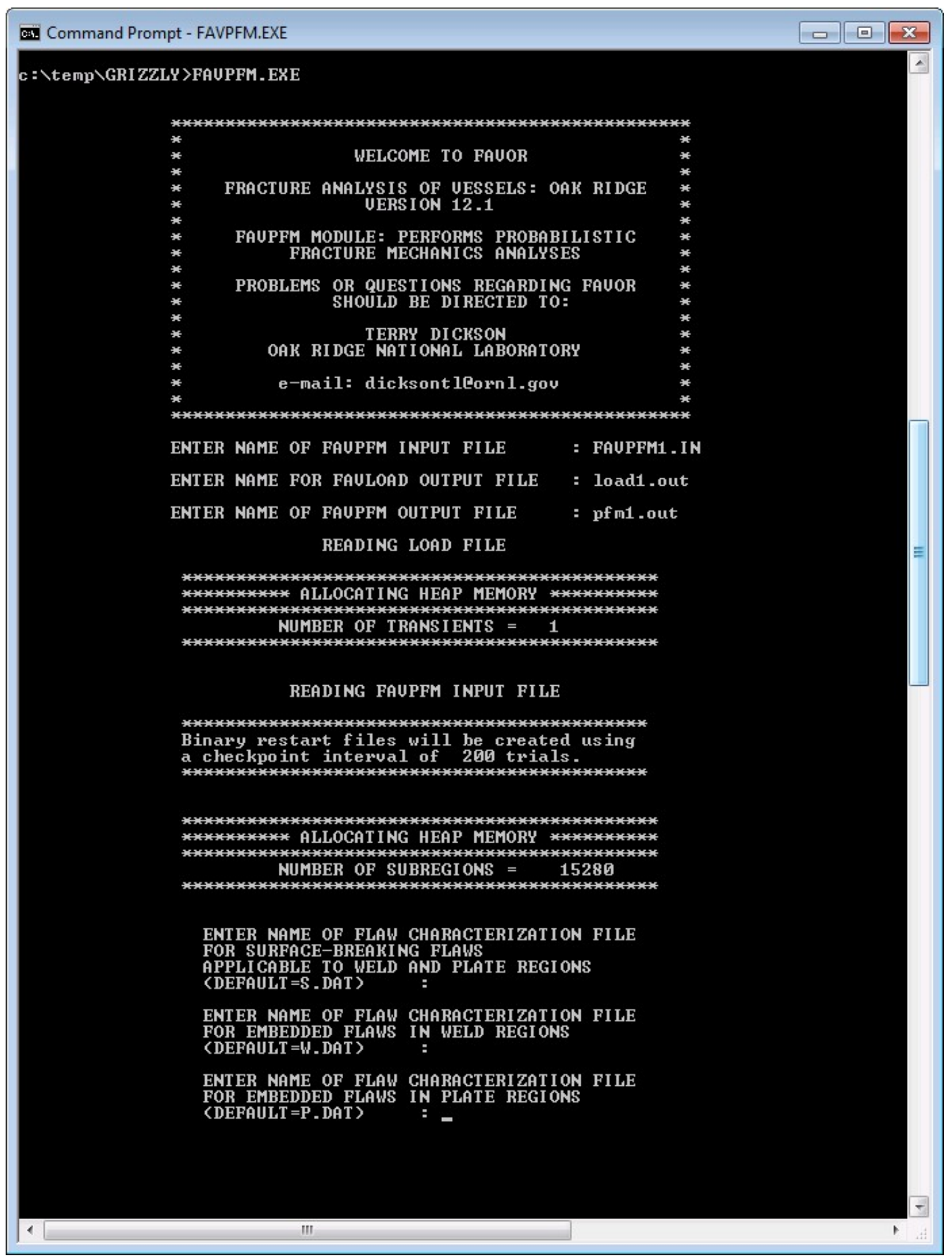

Figure 20. FAVPFM prompts for the names of the (1) FAVPFM input file, (2) FAVLoadgenerated load-definition file, (3) FAVPFM output file, (4) flaw-characterization file for surface-breaking flaws in welds and plates, (5) flaw-characterization file for embedded flaws in welds, and (6) flaw-characterization file for embedded flaws in plates. 


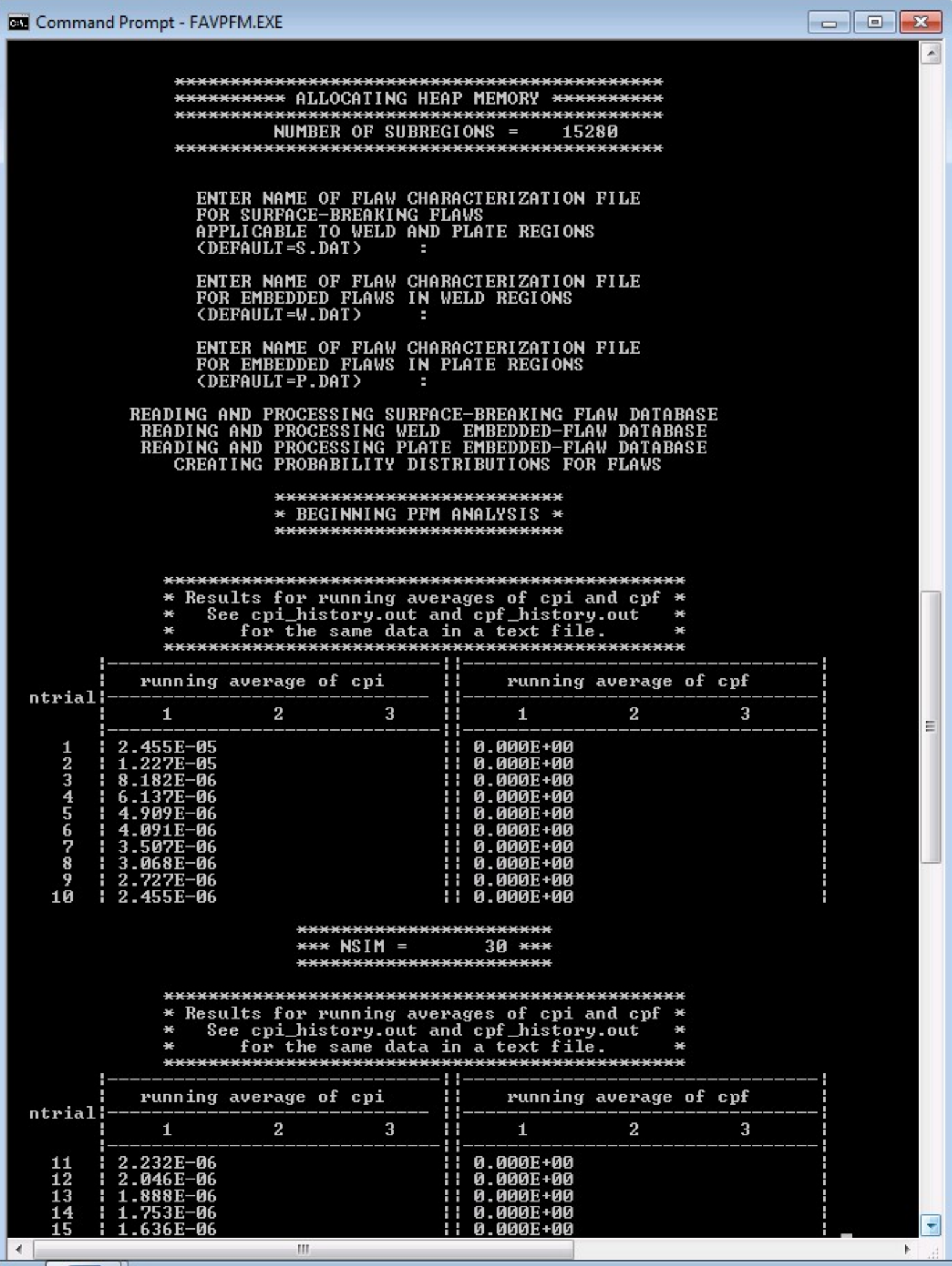

Figure 21. FAVPFM continually writes out progress reports in terms of running average $\mathrm{CPI} / \mathrm{CPF}$ values for each transient as the code proceeds through the required number of RPV trials. 


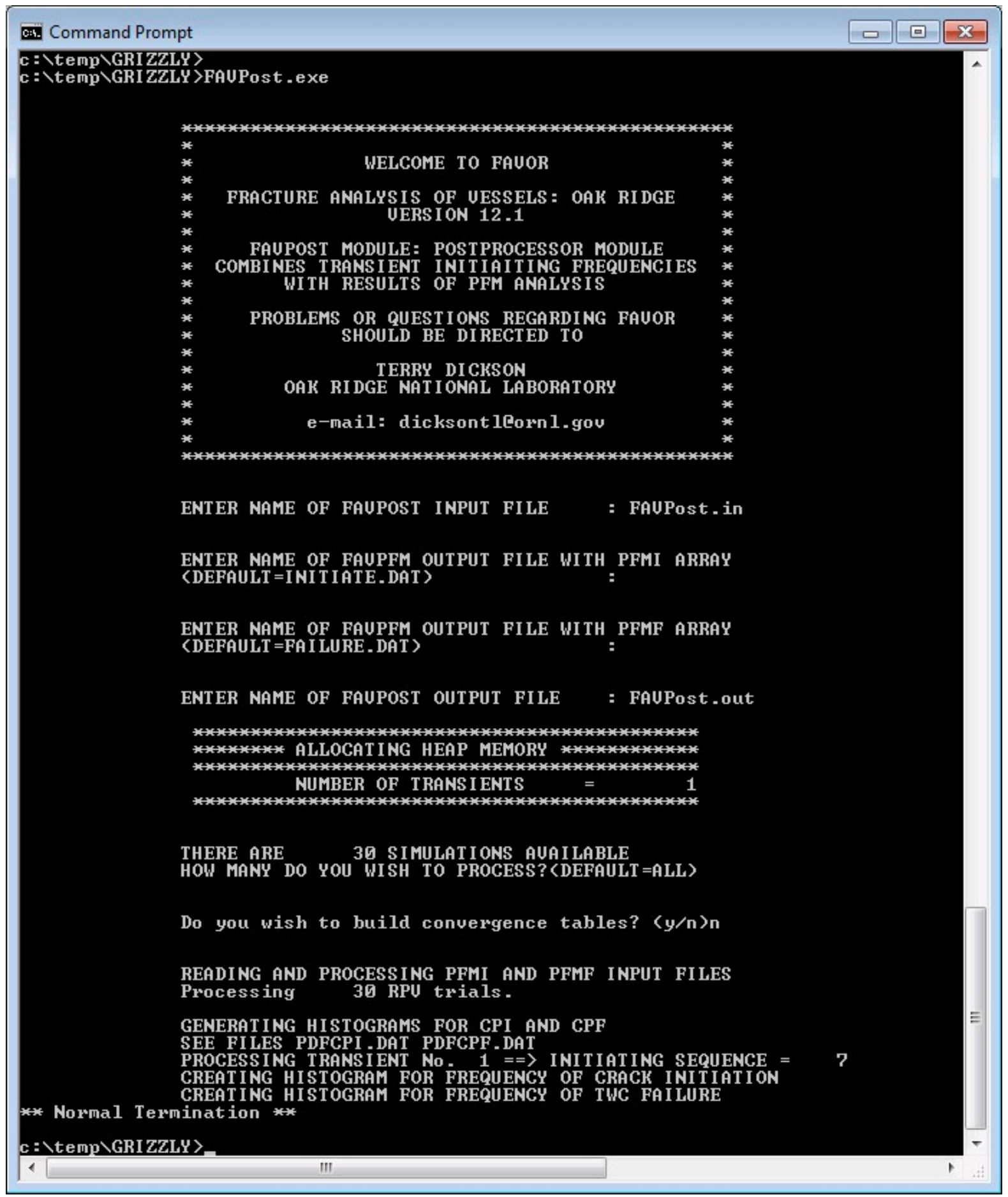

Figure 22. Type in FAVPost at the Command Prompt to execute the FAVPost module. FAVPost prompts for the (1) FAVPost input file, (2) CPI matrix file generated by FAVPFM, (3) CPF matrix file generated by FAVPFM, and (4) the FAVPost output file. Set the total number of simulations to be processed and build convergence tables, if required. 


\subsection{Contacts}

To obtain a copy of the Grizzly/FAVOR Interface executables, pleaes contact:

- Jeremy Busby: busbyjt at ornl dot gov 


\section{CONCLUSIONS AND FUTURE SUGGESTIONS}

This document describes the implementation of the Grizzly/FAVOR Interface project. The objective of the Grizzly/FAVOR Interface is to create the capability to apply Grizzly 3-D finite element (thermal and stress) analysis results as input to FAVOR probabilistic fracture mechanics (PFM) analyses. The one benefit of FAVOR to Grizzly is the PROBABILISTIC capability. This document detailed the implementation of the Grizzly/FAVOR Interface, the preliminary verification and tests results and a user guide that provided detailed step-by-step instructions to run the program.

A work plan for developing a Fracture Mechanics Assessment Capability in Grizzly has been written to detail the future work in [5, ORNL-2013-44107]. 


\section{REFERENCES}

1. P. T. Williams, T. L. Dickson, and S. Yin, Fracture Analysis of Vessels - FAVOR (v12.1)

2. T. L. Dickson, P. T. Williams and S. Yin, Fracture Analysis of Vessels - FAVOR (v12.1) Computer Code: User's Guide, ORNL/TM-2012/566, Oak Ridge National Laboratory, Oak Ridge, TN, 2012.

3. Light Water Reactor Sustainability Program - Integrated Program Plan, INL/EXT-11-23452, Idaho National Laboratory, Idaho Falls, ID, January 2012.

4. B. Spencer, J. Busby, R. Martineau, B. Wirth, A Proof of Concept: Grizzly, The LWRS Programs Materials Aging and Degradation Pathway Main Simulation Tool.

5. B.R. Bass, T.L. Dickson, H.B. Klasky, and P.T. Williams, Work Plan for Developing a Fracture Mechanics Assessment Capability in GRIZZLY, ORNL-2013-44107, June 2013. 